Article

\title{
Profiling of Concanavalin A-Binding Glycoproteins in Human Hepatic Stellate Cells Activated with Transforming Growth Factor- $\beta 1$
}

\author{
Yannan Qin ${ }^{1, \dagger}$, Yaogang Zhong ${ }^{2, \dagger}$, Ganglong Yang ${ }^{2}$, Tianran Ma ${ }^{2}$, Liyuan Jia ${ }^{2}$, \\ Chen Huang ${ }^{1, *}$ and $\mathrm{Zheng} \mathrm{Li}^{2, *}$
}

1 Department of Genetics and Molecular Biology, Xi'an Jiaotong University College of Medicine, Xi'an 710061, Shaanxi, China; E-Mail: yannan159@mail.xjtu.edu.cn

2 Laboratory for Functional Glycomics, College of Life Sciences, Northwest University, Xi'an 710069, Shaanxi, China; E-Mails: zhongyglyco@163.com (Y.Z.); glyanglife@hotmail.com (G.Y.); rooroo@163.com (T.M.); csshxzza@163.com (L.J.)

$\dagger$ These authors contributed equally to this work.

* Authors to whom correspondence should be addressed; E-Mails: zhengli@nwu.edu.cn (Z.L.); hchen@mail.xjtu.edu.cn (C.H.); Tel.: +86-29-8830-4104 (Z.L.); +86-29-8265-7723 (C.H.); Fax: +86-29-8830-3572 (Z.L.).

External Editors: Vito Ferro and Trinidad Velasco-Torrijos

Received: 27 September 2014; in revised form: 18 November 2014 / Accepted: 24 November 2014 / Published: 28 November 2014

\begin{abstract}
Glycoproteins play important roles in maintaining normal cell functions depending on their glycosylations. Our previous study indicated that the abundance of glycoproteins recognized by concanavalin A (ConA) was increased in human hepatic stellate cells (HSCs) following activation by transforming growth factor- $\beta 1$ (TGF- $\beta 1$ ); however, little is known about the ConA-binding glycoproteins (CBGs) of HSCs. In this study, we employed a targeted glycoproteomics approach using lectin-magnetic particle conjugate-based liquid chromatography-tandem mass spectrometry to compare CBG profiles between LX-2 HSCs with and without activation by TGF- $\beta 1$, with the aim of discovering novel CBGs and determining their possible roles in activated HSCs. A total of 54 and 77 proteins were identified in the quiescent and activated LX-2 cells, respectively. Of the proteins identified, $14.3 \%$ were glycoproteins and $73.3 \%$ were novel potential glycoproteins. Molecules involved in protein processing in the endoplasmic reticulum
\end{abstract}


(e.g., calreticulin) and calcium signaling (e.g., 1-phosphatidylinositol-4,5-bisphosphate phosphodiesterase $\beta-2$ [PLCB2]) were specifically identified in activated LX-2 cells. Additionally, PLCB2 expression was upregulated in the cytoplasm of the activated LX-2 cells, as well as in the hepatocytes and sinusoidal cells of liver cirrhosis tissues. In conclusion, the results of this study may aid future investigations to find new molecular mechanisms involved in HSC activation and antifibrotic therapeutic targets.

Keywords: ConA-binding glycoprotein; hepatic stellate cells; transforming growth factor- $\beta 1$; mass spectrometry; peptides; KEGG pathway

\section{Introduction}

Liver fibrosis is a major complication of various chronic hepatic diseases, resulting from increased production and decreased degradation of the extracellular matrix. Activation and phenotypic transformation of hepatic stellate cells (HSCs) play a central role in the development and resolution of liver fibrosis and cirrhosis [1,2], and in the promotion of hepatocellular carcinoma [3]. Transforming growth factor- $\beta 1$ (TGF- $\beta 1$ ), as the key fibrogenic cytokine [4,5], activates HSCs via the TGF $\beta 1 /$ activin receptor-like kinase 1 (ALK1)/Smad1 pathway and stimulates collagen transcription in HSCs [6].

Glycosylation is the major posttranslational modification to the secretory and the membrane-anchored proteins in eukaryotic cells [7], which plays important roles in cell-cell adhesion, bacterial infection, viral attachment, ligand-receptor binding, and other key cellular processes [8]. In recent years, a growing number of studies have reported that protein glycosylations are frequently altered during physiological and pathological changes [9-11]. Many receptor-ligand interactions lead to alteration of protein-bound glycans, and numerous receptors are regulated by glycosylation to a lesser or greater degree; for example, Notch receptors are the recipient substrates of specific glycosyltransferases [12,13], which regulate the activation of Notch by its ligands and thus affect various processes during development. In HSCs, interleukin-1 and tumor necrosis factor- $\alpha$ have lectin-like activities [14] and recognize disialylated diantennary N-glycans bearing two Neu5Aca2,3 residues [15] and heparin [16,17], respectively. Our previous study also indicated that concanavalin A (ConA) and six other lectins showed stronger binding to the activated HSCs than to the quiescent HSCs [18].

Lectins are carbohydrate-binding proteins that discriminate terminal glycans based on subtle differences in their structures, which can be exploited in the laboratory to detect or isolate specific carbohydrate structures of glycoconjugates, including glycoproteins and glycolipids as well as glycosaminoglycans [19,20]. Along with the rapid improvement of cutting-edge separation technologies coupled with mass spectrometry in the fields of glycoproteomics and glycomics, glycoproteins can be enriched for analysis by hydrazide chemistry [21,22], lectin affinity [23,24], immunoaffinity [25,26], boric acid chemistry [27,28], size exclusion chromatography [29,30], hydrophilic interaction [31,32], and other methods. Lectin affinity chromatography is a unique method that can isolate glycoproteins/glycopeptides containing similar terminal glycan structures from complex samples. 
In this study, we employed a targeted glycoproteomics approach using lectin-magnetic particle conjugate-based liquid chromatography-tandem mass spectrometry (LC-MS/MS) to compare the profiles of ConA-binding glycoproteins (CBGs) between human HSCs (LX-2 cell line) with and without activation by TGF- $\beta 1$. The aim of this study was to determine whether any novel CBGs may be differentially expressed in the activated, compared with quiescent LX-2 cells, and consider the potential roles that these CBGs may play in the pathophysiology of liver fibrosis.

\section{Results and Discussion}

\subsection{Isolation of Con A-Binding Glycoproteins (CBGs) from LX-2 Cells}

ConA-magnetic particle conjugates (CMPCs) were used to isolate CBGs from total protein lysates of the activated and quiescent LX-2 cells. The total, unbound, and eluted proteins were resolved by SDS-PAGE and visualized by silver staining. The results showed that the bands of CBGs (Figure 1A, lanes 5 and 6) were complementary to those of the unbound proteins (lanes 3 and 4), and that the eluted CBGs were enriched to some degree from the total proteins (lanes 1 and 2) (Figure 1A).

Figure 1. SDS-PAGE analysis and MS identification of the isolated CBGs. (A) Proteins were resolved on $10 \%$ SDS gels and stained with silver staining. Lanes 1 and 2 showed total proteins, lanes 3 and 4 showed the unbound proteins, and lanes 5 and 6 showed the enriched CBGs from the quiescent and the activated LX-2 cells, respectively; (B) The Venn diagrams present the numbers of peptides and glycoproteins identified by MS. Left, the quiescent LX-2 cells; right, the activated LX-2 cells.
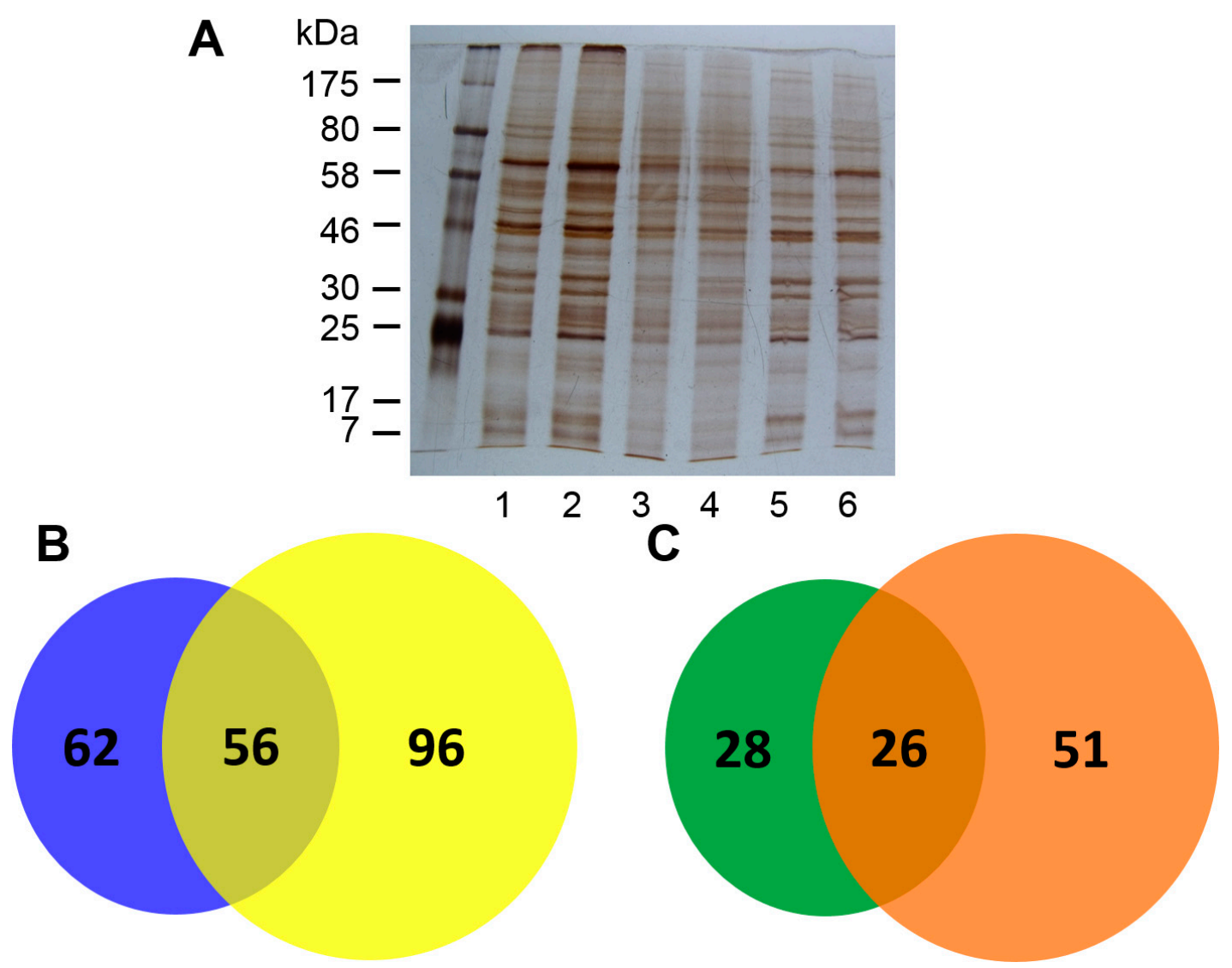


\subsection{Identification of CBGs Isolated by CMPCs by LC-MS/MS}

CBGs isolated by CMPCs from total proteins of the activated and quiescent LX-2 cells were identified by Agilent 6530 accurate-mass Q-TOF LC-MS/MS. A total of 118 and 152 unique peptides were identified, respectively, from the quiescent and activated LX-2 cells, and these peptides represented 54 and 77 proteins, respectively (Figure 1B,C). Then, the percentage amounts by which emPAI-based protein abundance estimates deviated from the actual measured values were calculated to permit the analysis and comparison of protein expression between the activated and quiescent LX-2 cells. As a result, four proteins (calreticulin [CALR], histone H4, galectin [LGALS]1, and isoform 1 of nucleoside diphosphate kinase A) were upregulated (fold-change $>2$ ), and two proteins (14-3-3 protein $\zeta / \delta$ and protein disulfide-isomerase) were downregulated in the activated LX-2 cells (fold-change $<0.5$ ). In addition, 28 proteins (including 14-3-3 protein $\varepsilon$, protease serine 4 isoform B, and 14-3-3 protein $\gamma$ ) were specifically identified in the quiescent LX-2 cells and 51 proteins (including isoform 2 of procollagen-lysine, 2-oxoglutarate 5-dioxygenase 2, POTE ankyrin domain family member F, and vimentin) were specifically identified in the activated LX-2 cells. In total, by mapping to the Uniprot database, $13(12.4 \%)$ of the identified proteins were classified as unreviewed proteins, 15 proteins (14.3\%) were classified as glycoproteins, and 77 proteins $(73.3 \%)$ were classified as unknown proteins (Table 1). According to two online glycosylation site prediction servers (NetNGlyc 1.0 [33] and NetOGlyc 4.0 [34]), 62 of the 77 "unknown" proteins were predicted to have potential N-glycosylation sites, and 15 proteins were predicted to have potential O-glycosylation sites. There were still three proteins that were not identified as glycoproteins by the online servers (Table 1).

Lectins are defined as carbohydrate-binding proteins that are neither antibodies nor enzymes, which have a wide range of glycan-binding specificities, and are therefore suitable for the partial isolation and characterization of a glycome. ConA is a lectin originally extracted from the jack-bean Canavalia ensiformis, which binds specifically to internal and nonreducing terminal $\alpha$-D-mannosyl ( $\alpha$-Man) and $\alpha$-D-glucosyl groups ( $\alpha$-Glu) [35]. In this study, two possible consequences of the affinity attachment of CBGs to ConA were considered. First, total proteins were extracted under non-denaturing conditions; therefore, some non-target proteins that interacted with CBGs might have been pulled down together. Second, ConA is known to be a glycoprotein containing N-glycans linked to the 152th amino acid (Asn) for each sub-unit [36], and therefore, it was inevitable that cellular glycan-binding proteins with an affinity for the glycans of ConA might also have been collected by CMPCs. These two factors, together with the addition of the possible unusual O-glycosylations (e.g., O-mannosylation and O-GlcNAc) of the CBGs may explain the identification of some "non-glycoproteins" by MS (Table 1). To solve those two problems as effectively as possible, denaturing rinses were conducted several times with $0.1 \%(\mathrm{v} / \mathrm{v})$ Tween $^{\circledR} 20$, and specific competitive elution was performed with $0.5 \mathrm{M}$ methyl- $\alpha$-D-mannose and $0.2 \mathrm{M}$ methyl- $\alpha$-D-glucose. 
Table 1. Detailed information about the CBGs (ConA-binding glycoproteins) isolated by CMPCs (ConA-magnetic particle conjugates) from activated and quiescent LX-2 cells.

\begin{tabular}{|c|c|c|c|c|c|c|c|c|}
\hline No. & Accession & Description & Gene Name & Search Score & Coverage \% & A/Q Ratio ${ }^{a}$ & $\mathbf{Q}$ or $\mathbf{A}^{\mathbf{b}}$ & Known $^{\mathrm{c}}$ \\
\hline 1 & IPI00003865 & Isoform 1 of Heat shock cognate $71 \mathrm{kDa}$ protein & HSPA8 & 375 & 26.8 & - & $\mathrm{Q}, \mathrm{A}$ & $\mathrm{P}^{\mathrm{N}}$ \\
\hline 2 & IPI00022434 & Putative uncharacterized protein ALB & ALB & 260 & 6.5 & - & $\mathrm{Q}, \mathrm{A}$ & $\mathrm{Y}^{\mathrm{N}}$ \\
\hline 3 & IPI00021263 & 14-3-3 protein zeta/delta & YWHAZ & 164 & 15.1 & 0.16 & $\mathrm{Q}, \mathrm{A}$ & $\mathrm{P}^{\mathrm{N}}$ \\
\hline 4 & IPI00010796 & Protein disulfide-isomerase & P4HB & 109 & 17.5 & 0.5 & $\mathrm{Q}, \mathrm{A}$ & $\mathrm{P}^{\mathrm{N}}$ \\
\hline 5 & IPI00011134 & Putative heat shock $70 \mathrm{kDa}$ protein 7 & HSPA7 & 96 & 6.5 & - & $\mathrm{Q}, \mathrm{A}$ & $\mathrm{P}^{\mathrm{N}}$ \\
\hline 6 & IPI00220327 & Keratin, type II cytoskeletal 1 & KRT1 & 92 & 3.4 & - & $\mathrm{Q}, \mathrm{A}$ & $\mathrm{P}^{\mathrm{N}}$ \\
\hline 7 & IPI00009865 & Keratin, type I cytoskeletal 10 & KRT10 & 75 & 14.6 & - & $\mathrm{Q}, \mathrm{A}$ & $\mathrm{P}^{\mathrm{N}}$ \\
\hline 8 & IPI00217966 & Isoform 1 of L-lactate dehydrogenase A chain & LDHA & 68 & 4.5 & - & $\mathrm{Q}, \mathrm{A}$ & $\mathrm{P}^{\mathrm{N}}$ \\
\hline 9 & IPI00021439 & Actin, cytoplasmic 1 & ACTB & 65 & 17.9 & - & $\mathrm{Q}, \mathrm{A}$ & $\mathrm{P}^{\mathrm{N}}$ \\
\hline 10 & IPI01969230 & LOC644914; H3F3B; LOC440926; H3F3A Histone H3;xx & Null & 60 & 8.9 & - & $\mathrm{Q}, \mathrm{A}$ & Null \\
\hline 11 & IPI00418471 & Vimentin & VIM & 56 & 2.1 & - & $\mathrm{Q}, \mathrm{A}$ & $\mathrm{Y}^{\circ}$ \\
\hline 12 & IPI00020599 & Calreticulin & CALR & 53 & 10.8 & 2.44 & $\mathrm{Q}, \mathrm{A}$ & $\mathrm{Y}^{\mathrm{N}}$ \\
\hline 13 & IPI00183968 & tropomyosin alpha-3 chain isoform 1 & TPM3 & 53 & 7.4 & - & $\mathrm{Q}, \mathrm{A}$ & $\mathrm{P}^{\mathrm{N}}$ \\
\hline 14 & IPI00218820 & Isoform 3 of Tropomyosin beta chain & TPM2 & 53 & 8.9 & - & $\mathrm{Q}, \mathrm{A}$ & $\mathrm{P}^{\mathrm{N}}$ \\
\hline 15 & IPI00293665 & Keratin, type II cytoskeletal 6B & KRT6B & 49 & 4.4 & - & $\mathrm{Q}, \mathrm{A}$ & $\mathrm{P}^{\mathrm{N}}$ \\
\hline 16 & IPI00453473 & Histone $\mathrm{H} 4$ & HIST1H4H & 36 & 29.1 & 3.13 & $\mathrm{Q}, \mathrm{A}$ & $\mathrm{P}^{\circ}$ \\
\hline 17 & IPI00003269 & Beta-actin-like protein 2 & ACTBL2 & 32 & 6.6 & - & $\mathrm{Q}, \mathrm{A}$ & $\mathrm{P}^{\mathrm{N}}$ \\
\hline 18 & IPI00216783 & ubiquitin carboxyl-terminal hydrolase 2 isoform $b$ & USP2 & 32 & 2.3 & - & $\mathrm{Q}, \mathrm{A}$ & $\mathrm{P}^{\circ}$ \\
\hline 19 & IPI00219219 & Galectin-1 & LGALS1 & 29 & 8.9 & 2.8 & $\mathrm{Q}, \mathrm{A}$ & $\mathrm{P}^{\mathrm{N}}$ \\
\hline 20 & IPI00009636 & Membrane-spanning 4-domains subfamily A member 7 & MS4A7 & 28 & 7.1 & - & $\mathrm{Q}, \mathrm{A}$ & $\mathrm{N}$ \\
\hline 21 & IPI00375617 & Isoform 2 of Abhydrolase domain-containing protein 12B & ABHD12B & 26 & 2.1 & - & $\mathrm{Q}, \mathrm{A}$ & $\mathrm{P}^{\circ}$ \\
\hline 22 & IPI00012048 & Isoform 1 of Nucleoside diphosphate kinase A & NME1-NME2 & 24 & 11.2 & 2.73 & $\mathrm{Q}, \mathrm{A}$ & $\mathrm{N}$ \\
\hline 23 & IPI00005685 & Paraneoplastic antigen Ma1 & PNMA1 & 22 & 3.7 & - & $\mathrm{Q}, \mathrm{A}$ & $\mathrm{P}^{\mathrm{N}}$ \\
\hline 24 & IPI00022774 & Transitional endoplasmic reticulum ATPase & VCP & 22 & 3 & - & $\mathrm{Q}, \mathrm{A}$ & $\mathrm{P}^{\mathrm{N}}$ \\
\hline 25 & IPI00470859 & Putative uncharacterized protein DKFZp686C04126 & MAN1B1 & 22 & 0.8 & - & $\mathrm{Q}, \mathrm{A}$ & $\mathrm{P}^{\circ}$ \\
\hline 26 & IPI00888712 & actin, beta-like 3 & POTEE & 20 & 2.6 & - & $\mathrm{Q}, \mathrm{A}$ & $\mathrm{P}^{\mathrm{N}}$ \\
\hline
\end{tabular}


Table 1. Cont.

\begin{tabular}{|c|c|c|c|c|c|c|c|c|}
\hline No. & Accession & Description & Gene Name & Search Score & Coverage \% & A/Q Ratio ${ }^{\text {a }}$ & Q or $\mathbf{A}^{\mathbf{b}}$ & Known $^{\mathrm{c}}$ \\
\hline 27 & IPI00000816 & 14-3-3 protein epsilon & YWHAE & 116 & 14.5 & 0.01 & Q & $\mathrm{P}^{\mathrm{N}}$ \\
\hline 28 & IPI00385250 & Protease serine 4 isoform B & PRSS3 & 75 & 9.6 & 0.01 & $\mathrm{Q}$ & $\mathrm{P}^{\mathrm{N}}$ \\
\hline 29 & IPI00013508 & Alpha-actinin-1 & ACTN1 & 61 & 1.3 & 0.01 & Q & $\mathrm{P}^{\mathrm{N}}$ \\
\hline 30 & $\underline{\text { IPI00451401 }}$ & Triosephosphate isomerase & TPI1 & 17 & 7.4 & 0.01 & Q & $\mathrm{P}^{\mathrm{N}}$ \\
\hline 31 & IPI00220642 & 14-3-3 protein gamma & YWHAG & 58 & 15 & 0.01 & Q & $\mathrm{P}^{\mathrm{N}}$ \\
\hline 32 & IPI00465028 & TPI1 triosephosphate isomerase isoform 2 & TPI1P1 & 56 & 18.9 & 0.01 & Q & $\mathrm{P}^{\mathrm{N}}$ \\
\hline 33 & IPI00479722 & Proteasome activator complex subunit 1 & PSME1 & 56 & 4.4 & 0.01 & Q & $\mathrm{P}^{\mathrm{N}}$ \\
\hline 34 & IPI00453476 & $29 \mathrm{kDa}$ protein & Null & 37 & 15.7 & 0.01 & Q & Null \\
\hline 35 & IPI00021304 & Keratin, type II cytoskeletal 2 epidermal & KRT2 & 33 & 4.5 & 0.01 & Q & $\mathrm{P}^{\mathrm{N}}$ \\
\hline 36 & IPI00008527 & $60 S$ acidic ribosomal protein $\mathrm{P} 1$ & RPLP1 & 32 & 14 & 0.01 & Q & $\mathrm{P}^{\mathrm{N}}$ \\
\hline 37 & IPI00021428 & Actin, alpha skeletal muscle & ACTA1 & 26 & 15.6 & 0.01 & Q & $\mathrm{P}^{\mathrm{N}}$ \\
\hline 38 & IPI00479743 & Isoform 1 of POTE ankyrin domain family member E & POTEKP & 26 & 5.8 & 0.01 & Q & $\mathrm{P}^{\mathrm{N}}$ \\
\hline 39 & IPI00009791 & Isoform WB of Plasma membrane calcium-transporting ATPase 2 & ATP2B2 & 25 & 0.7 & 0.01 & Q & $\mathrm{P}^{\mathrm{N}}$ \\
\hline 40 & IPI00014845 & Isoform 1 of Dynein heavy chain 8, axonemal & DNAH8 & 25 & 0.9 & 0.01 & Q & $\mathrm{P}^{\mathrm{N}}$ \\
\hline 41 & IPI00886949 & LOC100129520, similar to hCG2044193 & Null & 25 & 4.6 & 0.01 & Q & Null \\
\hline 42 & IPI00002850 & Hepatic leukemia factor & HLF & 24 & 4.1 & 0.01 & Q & $\mathrm{P}^{\mathrm{N}}$ \\
\hline 43 & IPI00550020 & Parathymosin & PTMS & 24 & 10.8 & 0.01 & Q & $\mathrm{P}^{\mathrm{N}}$ \\
\hline 44 & IPI00064885 & Zinc finger protein 3 homolog & ZFP3 & 23 & 1.8 & 0.01 & Q & $\mathrm{P}^{\mathrm{N}}$ \\
\hline 45 & IPI00925740 & ECT2 Protein & ECT2 & 20 & 47.8 & 0.01 & Q & $\mathrm{P}^{\mathrm{N}}$ \\
\hline 46 & IPI00002349 & Nuclear fragile X mental retardation-interacting protein 2 & NUFIP2 & 19 & 2.6 & 0.01 & Q & $\mathrm{P}^{\mathrm{N}}$ \\
\hline 47 & IPI00218667 & Stathmin-2 & STMN2 & 19 & 5 & 0.01 & Q & $\mathrm{P}^{\mathrm{N}}$ \\
\hline 48 & IPI00018146 & $14-3-3$ protein theta & YWHAQ & 18 & 9.8 & 0.01 & Q & $\mathrm{P}^{\mathrm{N}}$ \\
\hline 49 & IPI00156689 & Synaptic vesicle membrane protein VAT-1 homolog & VAT1 & 18 & 6.4 & 0.01 & Q & $\mathrm{P}^{\mathrm{N}}$ \\
\hline 50 & IPI00457114 & Isoform 1 of IQ motif and SEC7 domain-containing protein 1 & IQSEC1 & 18 & 3.7 & 0.01 & Q & $\mathrm{P}^{\mathrm{N}}$ \\
\hline 51 & IPI00797750 & $11 \mathrm{kDa}$ protein & Null & 17 & 16.7 & 0.01 & Q & Null \\
\hline 52 & IPI00938247 & LOC100287408, hypothetical protein XP_002344194 & Null & 17 & 8.8 & 0.01 & Q & Null \\
\hline 53 & IPI00966637 & Putative uncharacterized protein SDAD1 & SDAD1 & 17 & 23.9 & 0.01 & $\mathrm{Q}$ & $\mathrm{P}^{\mathrm{N}}$ \\
\hline
\end{tabular}


Table 1. Cont.

\begin{tabular}{|c|c|c|c|c|c|c|c|c|}
\hline No. & Accession & Description & Gene Name & Search Score & Coverage $\%$ & A/Q Ratio ${ }^{a}$ & Q or $\mathbf{A}^{\mathbf{b}}$ & Known $^{c}$ \\
\hline 54 & IPI00937642 & LOC100290701 hypothetical protein XP_002347764 & Null & 15 & 5.6 & 0.01 & Q & Null \\
\hline 55 & IPI00304925 & Heat shock $70 \mathrm{kDa}$ protein $1 \mathrm{~A} / 1 \mathrm{~B}$ & $\begin{array}{l}\text { HSPA1A; } \\
\text { HSPA1B }\end{array}$ & 85 & 9.2 & 100 & A & $\mathrm{P}^{\mathrm{N}}$ \\
\hline 56 & IPI00830052 & $62 \mathrm{kDa}$ protein & Null & 85 & 10.5 & 100 & A & Null \\
\hline 57 & IPI00015614 & Isoform A of Trypsin-3 & PRSS3 & 78 & 6.6 & 100 & A & $\mathrm{P}^{\circ}$ \\
\hline 58 & IPI00337495 & Isoform 2 of Procollagen-lysine,2-oxoglutarate 5-dioxygenase 2 & PLOD2 & 73 & 1.8 & 100 & A & $\mathrm{Y}^{\mathrm{N}}$ \\
\hline 59 & IPI00739539 & POTE ankyrin domain family member $F$ & POTEKP & 63 & 3.6 & 100 & A & $\mathrm{P}^{\mathrm{N}}$ \\
\hline 60 & IPI00000230 & tropomyosin alpha-1 chain isoform 2 & TPM1 & 59 & 7.7 & 100 & A & $\mathrm{P}^{\circ}$ \\
\hline 61 & IPI00013991 & Isoform 1 of Tropomyosin beta chain & TPM2 & 59 & 8.8 & 100 & A & $\mathrm{P}^{\circ}$ \\
\hline 62 & IPI00026260 & Isoform 1 of Nucleoside diphosphate kinase B & NME1-NME2 & 59 & 25 & 100 & A & $\mathrm{N}$ \\
\hline 63 & IPI00879437 & Protein disulfide-isomerase A1 & P4HB & 54 & 16.5 & 100 & A & $\mathrm{P}^{\circ}$ \\
\hline 64 & IPI00937995 & Actin-like protein (Fragment) & ACTB & 50 & 19.4 & 100 & A & $\mathrm{P}^{\circ}$ \\
\hline 65 & IPI00024320 & Putative RNA-binding protein 3 & RBM3 & 40 & 20.4 & 100 & A & $\mathrm{P}^{\circ}$ \\
\hline 66 & IPI00171611 & Histone $\mathrm{H} 3.2$ & HIST2H3A & 40 & 11.8 & 100 & A & $\mathrm{P}^{\mathrm{N}}$ \\
\hline 67 & IPI00798360 & SARNP $18 \mathrm{kDa}$ protein & SARNP & 40 & 4.3 & 100 & A & $\mathrm{P}^{\mathrm{N}}$ \\
\hline 68 & IPI00878173 & $\begin{array}{l}\text { cDNA FLJ39583 fis, clone SKMUS2004897, highly similar to } \\
\text { ACTIN, ALPHA SKELETAL MUSCLE }\end{array}$ & ACTA1 & 38 & 15.2 & 100 & $\mathrm{~A}$ & $\mathrm{P}^{\circ}$ \\
\hline 69 & IPI00045396 & Calumenin isoform 4 & CALU & 34 & 2.2 & 100 & A & $\mathrm{Y}^{\mathrm{N}}$ \\
\hline 70 & IPI00016768 & L-lactate dehydrogenase A-like 6B & LDHAL6B & 31 & 4.5 & 100 & A & $\mathrm{P}^{\mathrm{N}}$ \\
\hline 71 & IPI00784327 & $\begin{array}{c}\text { Isoform } 1 \text { of 1-phosphatidylinositol-4,5-bisphosphate } \\
\text { phosphodiesterase beta-2 }\end{array}$ & PLCB2 & 30 & 1.9 & 100 & A & $\mathrm{P}^{\mathrm{N}}$ \\
\hline 72 & IPI00000874 & Peroxiredoxin-1 & PRDX1 & 29 & 10.1 & 100 & A & $\mathrm{P}^{\mathrm{N}}$ \\
\hline 73 & IPI00216817 & HEAT repeat containing 7B1 & HEATR7B1 & 29 & 1.3 & 100 & A & $\mathrm{P}^{\mathrm{N}}$ \\
\hline 74 & IPI00293975 & $16 \mathrm{kDa}$ protein & Null & 29 & 6.2 & 100 & A & Null \\
\hline 75 & IPI00298622 & Intestinal-type alkaline phosphatase & ALPI & 29 & 2.1 & 100 & $\mathrm{~A}$ & $\mathrm{Y}^{\mathrm{N}}$ \\
\hline 76 & IPI00945706 & BOC Protein & $\mathrm{BOC}$ & 29 & 14.3 & 100 & $\mathrm{~A}$ & $\mathrm{P}^{\mathrm{N}}$ \\
\hline 77 & IPI00329801 & Annexin A5 & ANXA5 & 26 & 2.8 & 100 & A & $\mathrm{P}^{\circ}$ \\
\hline 78 & IPI00014424 & Elongation factor 1-alpha 2 & EEF1A2 & 25 & 3.9 & 100 & $\mathrm{~A}$ & $\mathrm{P}^{\mathrm{N}}$ \\
\hline 79 & IPI00030282 & Isoform 1 of Filensin & BFSP1 & 25 & 3.9 & 100 & A & $\mathrm{P}^{\circ}$ \\
\hline 80 & IPI00910689 & Polyserase- 2 & PRSS36 & 25 & 3.2 & 100 & $\mathrm{~A}$ & $\mathrm{Y}^{\mathrm{N}}$ \\
\hline
\end{tabular}


Table 1. Cont.

\begin{tabular}{|c|c|c|c|c|c|c|c|c|}
\hline No. & Accession & Description & Gene Name & Search Score & Coverage \% & A/Q Ratio ${ }^{a}$ & Q or $\mathbf{A}^{\mathbf{b}}$ & Known \\
\hline 81 & IPI00023673 & Galectin-3-binding protein & LGALS3BP & 24 & 3.8 & 100 & A & $\mathrm{Y}^{\mathrm{N}}$ \\
\hline 82 & IPI00414717 & Isoform 2 of Golgi apparatus protein 1 & GLG1 & 24 & 2.1 & 100 & A & $\mathrm{Y}^{\mathrm{N}}$ \\
\hline 83 & IPI00007249 & Ectonucleotide pyrophosphatase/phosphodiesterase family member 4 & ENPP4 & 23 & 5.7 & 100 & A & $\mathrm{Y}^{\mathrm{N}}$ \\
\hline 84 & IPI00008692 & Isoform 1 of Keratin, type I cuticular Ha6 & KRT36 & 23 & 4.9 & 100 & A & $\mathrm{P}^{\mathrm{N}}$ \\
\hline 85 & IPI00290077 & Keratin, type I cytoskeletal 15 & KRT15 & 23 & 4.4 & 100 & A & $\mathrm{P}^{\mathrm{N}}$ \\
\hline 86 & IPI00384497 & Protein-tyrosine phosphatase-like member B & PTPLB & 23 & 7.1 & 100 & A & $\mathrm{Y}^{\mathrm{N}}$ \\
\hline 87 & IPI00908888 & cDNA FLJ57836, highly similar to Myb-binding protein 1A & MYBBP1A & 23 & 2.2 & 100 & A & $\mathrm{P}^{\mathrm{N}}$ \\
\hline 88 & IPI00024658 & OTU domain-containing protein 7B & OTUD7B & 22 & 2.5 & 100 & A & $\mathrm{P}^{\circ}$ \\
\hline 89 & IPI00384972 & Isoform 1 of MLL1/MLL complex subunit KIAA1267 & KIAA1267 & 22 & 1.5 & 100 & A & $\mathrm{P}^{\mathrm{N}}$ \\
\hline 90 & IPI00394814 & Serine protease 55 & PRSS55 & 22 & 4.8 & 100 & A & $\mathrm{Y}^{\mathrm{N}}$ \\
\hline 91 & IPI00216704 & Isoform 2 of Spectrin beta chain, erythrocyte & SPTB I & 21 & 1.7 & 100 & A & $\mathrm{P}^{\mathrm{N}}$ \\
\hline 92 & IPI00455675 & Centrosomal protein of $192 \mathrm{kDa}$ & CEP192 & 20 & 1.1 & 100 & A & $\mathrm{P}^{\mathrm{N}}$ \\
\hline 93 & IPI00552749 & DNAH8 478 kDa protein & DNAH8 & 20 & 1.7 & 100 & A & $\mathrm{P}^{\mathrm{N}}$ \\
\hline 94 & IPI00748715 & SEPT9 protein (Fragment) & Null & 19 & 3.5 & 100 & A & Null \\
\hline 95 & IPI00020035 & Protein NipSnap homolog 3B & NIPSNAP3B & 18 & 12.6 & 100 & A & $\mathrm{P}^{\circ}$ \\
\hline 96 & IPI00217899 & E3 ubiquitin-protein ligase RNF168 & RNF168 & 18 & 1.9 & 100 & A & $\mathrm{P}^{\mathrm{N}}$ \\
\hline 97 & IPI00010289 & $\mathrm{D}(1 \mathrm{~A})$ dopamine receptor & DRD1 & 17 & 4 & 100 & A & $\mathrm{Y}^{\mathrm{N}}$ \\
\hline 98 & IPI00478586 & Isoform 2 of Vacuolar protein sorting-associated protein 13A & VPS13A & 17 & 1.9 & 100 & A & $\mathrm{P}^{\mathrm{N}}$ \\
\hline 99 & IPI00929137 & Conserved hypothetical protein & Null & 17 & 9.9 & 100 & A & Null \\
\hline 100 & IPI00011500 & Isoform 1 of Testicular acid phosphatase & ACPT & 16 & 2.8 & 100 & A & $\mathrm{Y}^{\mathrm{N}}$ \\
\hline 101 & IPI00299507 & Condensin complex subunit 2 & NCAPH & 16 & 0.9 & 100 & A & $\mathrm{P}^{\mathrm{N}}$ \\
\hline 102 & IPI00009101 & Isoform 2 of Helicase SRCAP & SRCAP & 15 & 1 & 100 & A & $\mathrm{P}^{\mathrm{N}}$ \\
\hline 103 & IPI00442299 & Isoform 1 of Neurexin-1-alpha & NRXN1 & 15 & 3.3 & 100 & A & $\mathrm{Y}^{\mathrm{N}}$ \\
\hline 104 & IPI00947233 & PCOLCE2 Protein & PCOLCE2 & 14 & 42.6 & 100 & A & $\mathrm{P}^{\mathrm{N}}$ \\
\hline 105 & IPI00294052 & Single-stranded DNA-binding protein 2 & SSBP2 & 13 & 3.6 & 100 & A & $\mathrm{P}^{\mathrm{N}}$ \\
\hline
\end{tabular}

a: Glycoproteins with an emPAI ratio of $>2.0$ or $<0.5$ are shown. "A/Q" represents the ratio of the emPAI value of a protein in the activated LX-2 cells $v s$. that in the quiescent LX-2 cells. The "A/Q" value of glycoproteins identified specifically in quiescent LX-2 was assigned as 0.01 , while that of glycoproteins identified specifically in the activated LX-2 was assigned as 100; ${ }^{b}$ : Data in column "Q or A" represent the CBG identified in the quiescent LX-2 (Q) or the activated LX-2 (A); ": "Y represents the CBGs annotated as "N-linked glycosylated" in Swiss-Prot; "Yo" represents the CBGs annotated as "O-linked glycosylated" in Swiss-Prot; "PN" represents potential N-linked glycoproteins predicted by the software NetNGlyc 1.0 Server; "Po" represents potential O-linked glycoproteins predicted by the software NetOGlyc 4.0 Server; "N" represents proteins with no typical glycosylation site. 


\subsection{GO Classification of the Identified CBGs Using Blast $2 G O^{\circledR}$}

To investigate the major biological functions of CBGs in LX-2 cells, the commercially available software program Blast2GO was used to analyze the proteins that were identified in LX-2 cells for functional enrichment according to three grouping classifications: cellular components, biological processes, and molecular functions (Figure 2A). Of 105 identified CBGs, 98 had gene ontology (GO) annotations available. In terms of cellular components, 62 proteins $(30.1 \%)$ were grouped as cell proteins, while 58 proteins $(28.2 \%)$ were grouped as organelle proteins. Moreover, other protein groupings were found, with groups including: cell membrane $(26,12.6 \%)$, macromolecular complex $(26,12.6 \%)$, membrane-enclosed lumen $(14,6.8 \%)$, and extracellular region $(10,4.9 \%)$. In terms of biological processes, about 48 proteins $(16.3 \%), 44$ proteins $(15.0 \%), 31$ proteins $(10.5 \%), 29$ proteins $(9.9 \%)$, and 27 proteins $(9.2 \%)$ were included in the groups of cellular process, single-organism process, biological regulation, metabolic process, and response to stimulus, respectively. In terms of molecular function, proteins with binding ability formed the largest group (30, 43.9\%) and other smaller groups identified included catalytic activity $(14,21.9 \%)$, structural molecule activity (11, $17.2 \%)$, and receptor activity $(3,4.7 \%)$. Detailed analysis of the binding ability group revealed that proteins with the ability to bind to proteins $(21,47.7 \%)$ and ions $(8,18.2 \%)$ comprised the most abundant subgroups. To determine whether there were any differences in the three aspects of GO annotations between activated and quiescent LX-2 cells, GO enrichment analysis was performed. Greater enrichment was found in the response to stimulus, detection of stimulus, activation of immune response, and gene silencing groups, while enrichment of the translation initiation and cell cycle process groups was much lesser in activated LX-2 cells than in the quiescent control cells (Figure 2B).

In our previous study, we found large differences in the distribution of glycoproteins bound among ConA and other lectins in LX-2 cells. The glycoproteins recognized by Aleuria aurantia lectin (AAL), Erythrina cristagalli lectin (ECA), and phytohemagglutinin (PHA-E) were mainly located on the cytoplasmic membrane and the perinuclear cytoplasm (i.e., the endoplasmic reticulum [ER] and Golgi complex), while ConA showed positive binding to the glycoproteins located in the whole cytoplasm and/or cytoplasmic membrane [18]. In the present study, 62 proteins (30.1\%) were grouped as intracellular proteins and $58(28.2 \%)$ as organelle proteins. Most of the proteins in the organelle proteins group were also included in the intracellular proteins group. It is known that the common protein-bound glycan adduct, $\mathrm{N}$-linked core oligosaccharide, is composed of two $\mathrm{N}$-acetylglucosamine, nine mannose, and three glucose residues, and this oligosaccharide molecule is synthesized and processed in the ER [37]. Glycans are subjected to extensive modifications as glycoproteins mature and move through the ER via the Golgi complex to their final destinations inside and outside the cell [38]. Con A can specifically recognize the trimannoside core of the N-glycan [39], so N-glycosylated proteins that are still undergoing processing and sorting in the ER and Golgi can also be recognized by ConA, in addition to the mature membrane and secreted glycoproteins. For some organelle proteins, such as Golgi glycoprotein 1 (GLG1) (Table 1) and lysosomal enzymes, their synthesis and positioning also depend on the glycosylation associated with ER-Golgi trafficking [40,41]. In addition, O-glycosylations such as O-GlcNAc, which contribute to nutrient sensing and regulation of insulin signaling, cell cycle, calcium signaling pathway, and cellular stress response [42-44], may contain 
multiple mannose residues that can also be recognized by ConA, since CBGs were distributed not only in the perinuclear cytoplasm of the LX-2 cells, but also in the whole cytoplasm and cell membrane.

Figure 2. The GO annotations of the identified CBGs in LX-2 cells. (A) Total CBGs identified in LX-2 cells were analyzed for functional enrichment according to the three grouping classifications of cellular component, biological process, and molecular function using the software Blast2 $\mathrm{GO}^{\circledR}$; (B) Gene ontology (GO) classification and comparison of enrichment of functional groups between the quiescent and the activated LX-2 cells was performed using WEGO software.
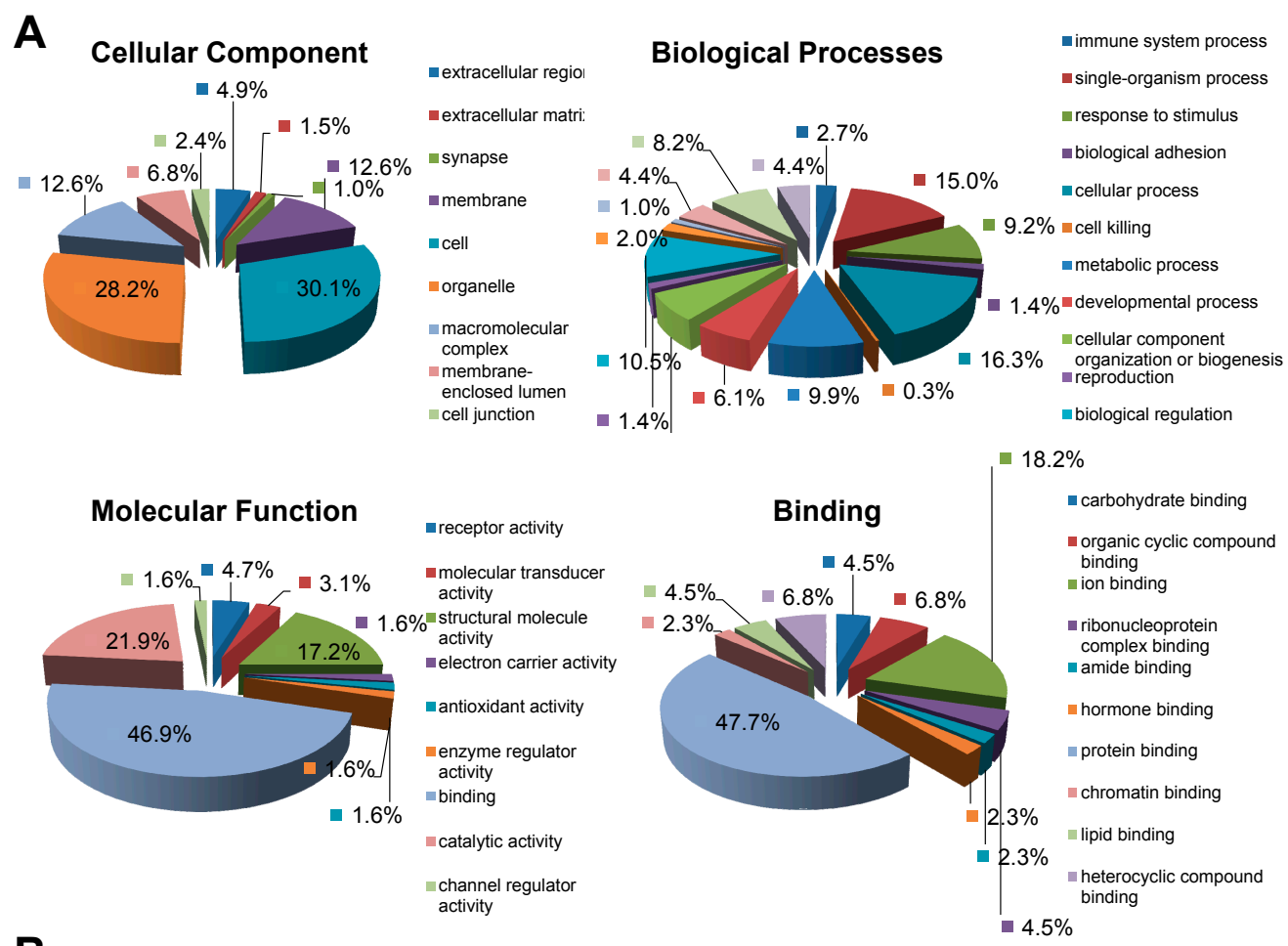

B

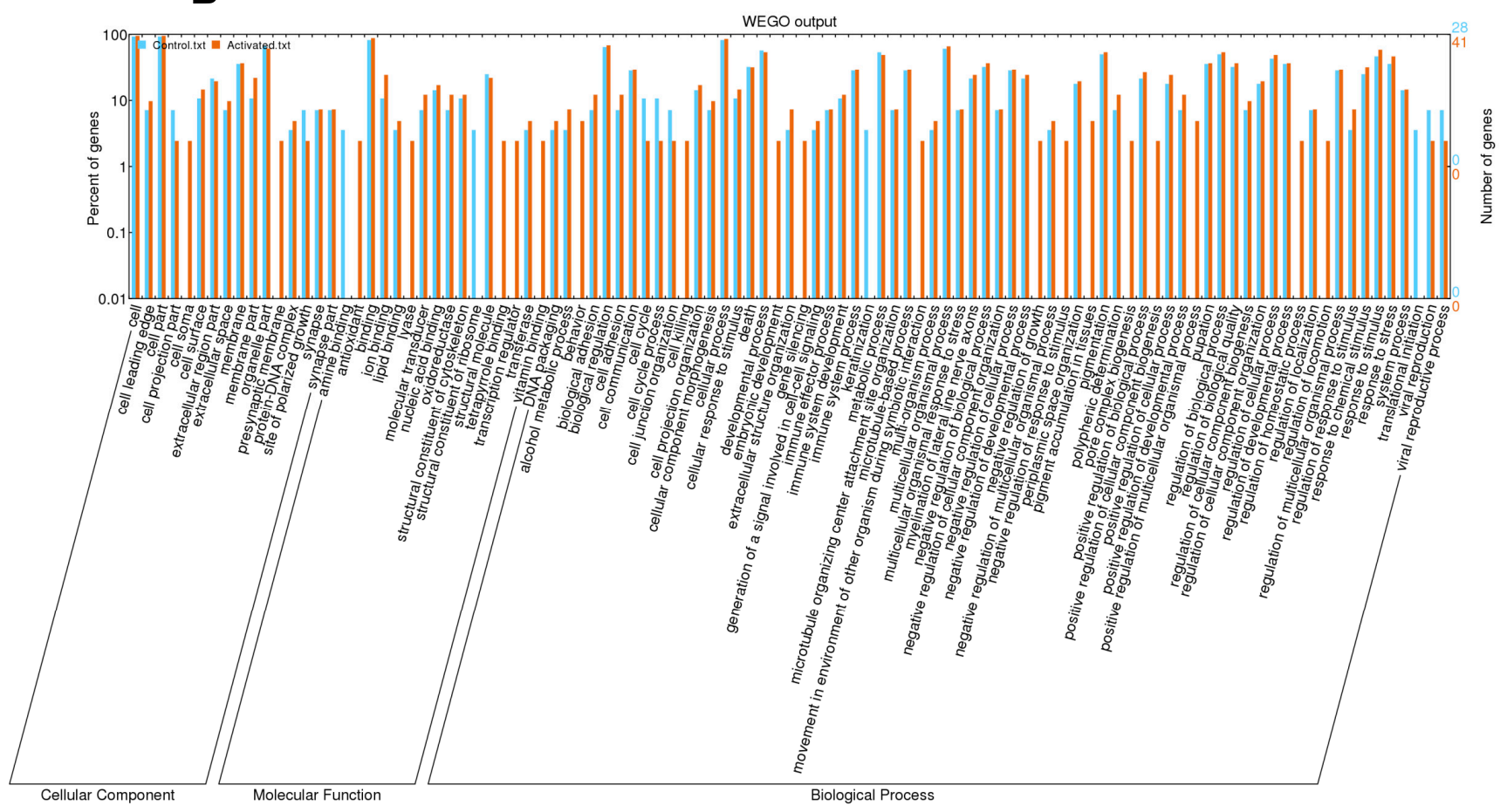




\subsection{KEGG Pathway Analysis and Functional Protein Association Networks}

In total, 91 of 105 identified CBGs had been annotated in DAVID Bioinformatics Resources version 6.7. These glycoproteins were mapped to 6 KEGG pathways with the thresholds of count of $>2$ and $p$ value of $<0.05$ compared with the background signal of the human genome; the identified KEGG pathways included protein processing in the ER, calcium signaling pathway, cell cycle, glycolysis/gluconeogenesis, and others (Figure 3A,B, Table S1). Proteins involved in protein processing in the ER (e.g., CALR, protein disulfide-isomerase A1, and heat shock 70-kDa protein 1A/1B) and calcium signaling pathway (e.g., D[1A] dopamine receptor [DRD1] and 1-phosphatidylinositol-4,5-bisphosphate phosphodiesterase $\beta-2$ ) were specifically identified or upregulated in the activated LX-2 cells. In contrast, 14-3-3 protein family members (e.g., 14-3-3 $\zeta / \delta$, 14-3-3 $\varepsilon$, and 14-3-3 $\gamma$ ) involved in the cell cycle and the neurotrophin signaling pathway were specifically identified in the quiescent LX-2 cells.

Figure 3. KEGG pathway analysis and functional protein association networks. (A,B) show the CBGs mapped to the KEGG pathways of protein processing in the ER and calcium signaling. The CBGs involved in these networks are labeled with a red frame; $(\mathbf{C}, \mathbf{D})$ display the potential interactions among total CBGs and show the CBGs that were determined to show significant correlations by STRING analysis.

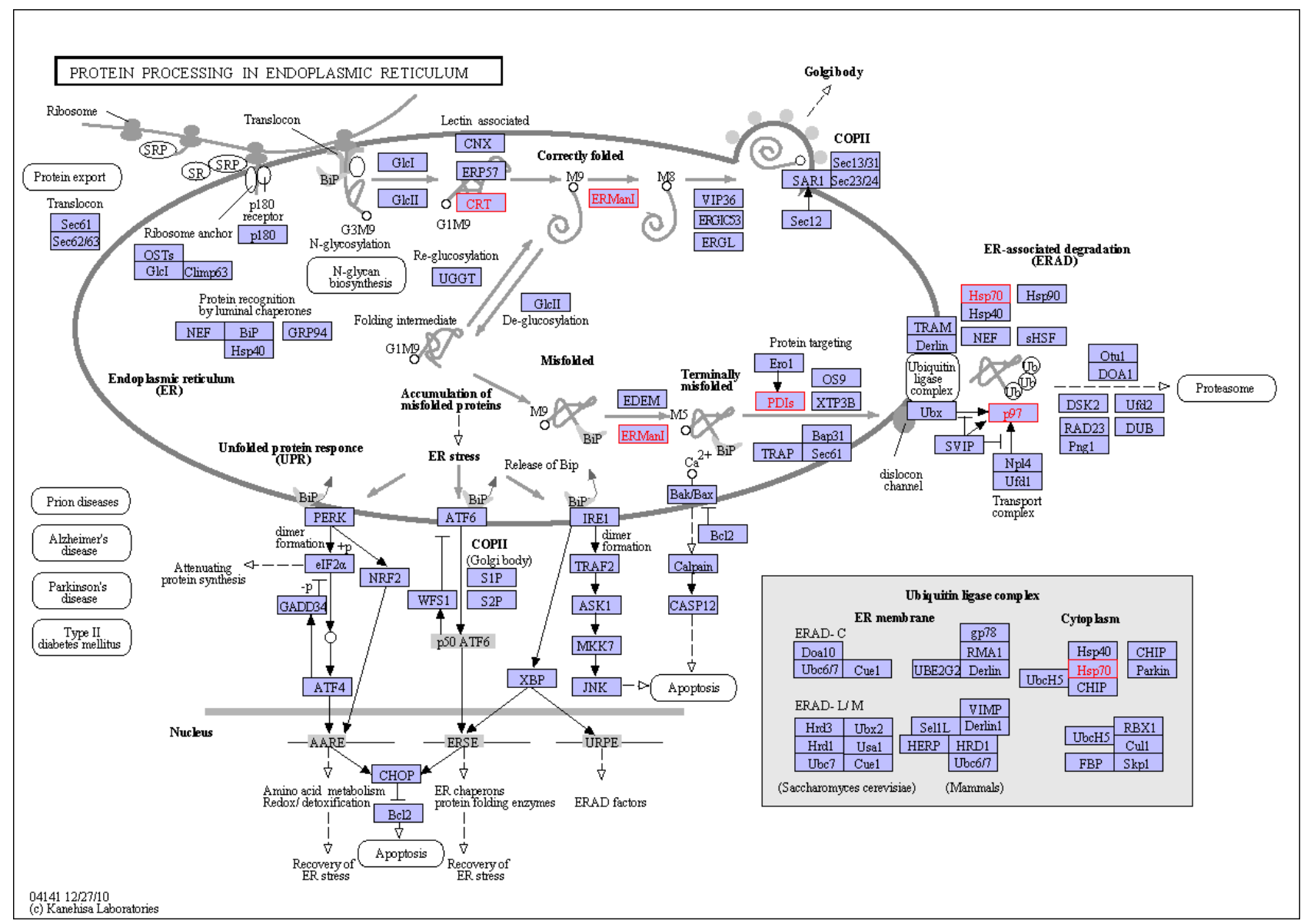


Figure 3. Cont.

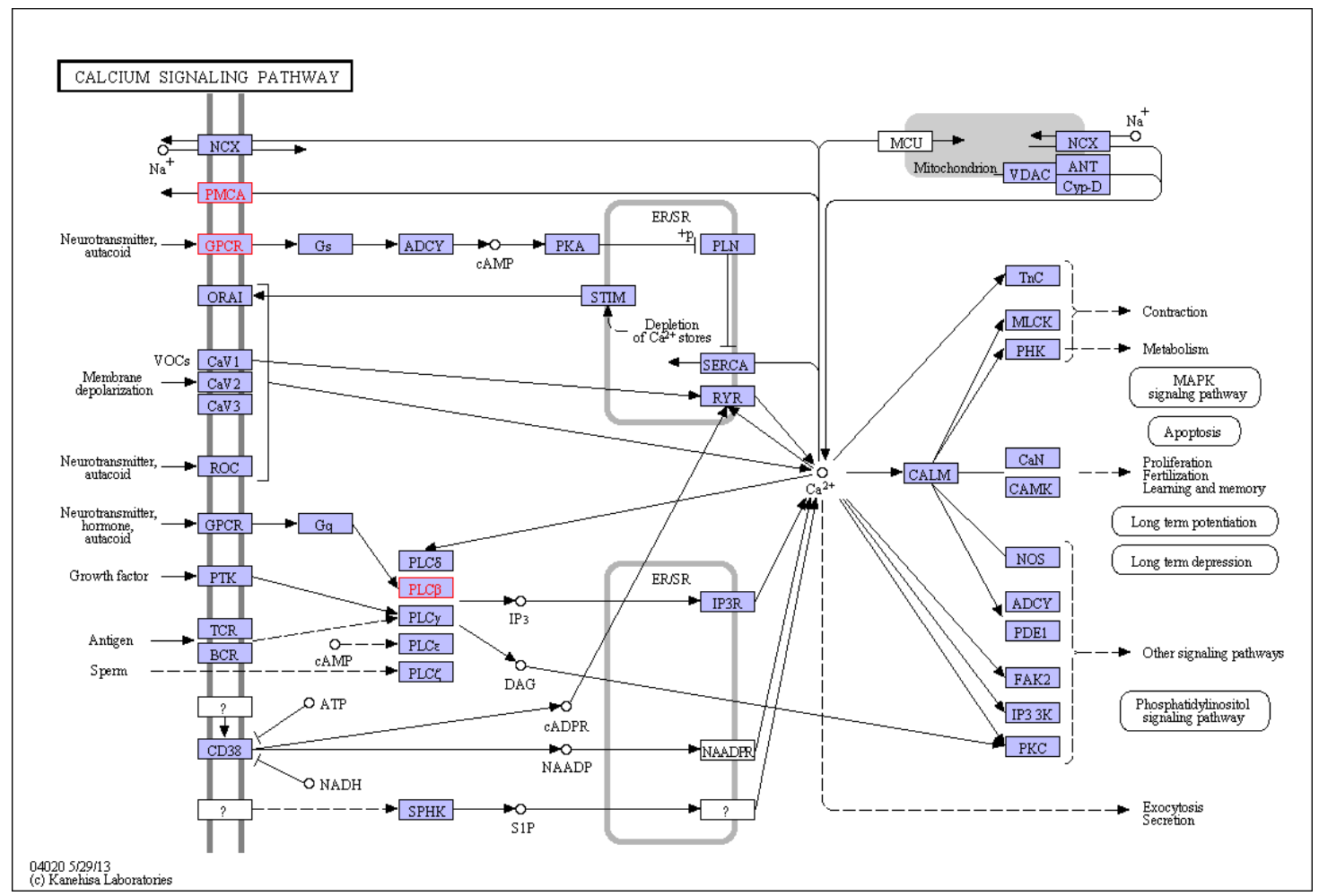

(B)

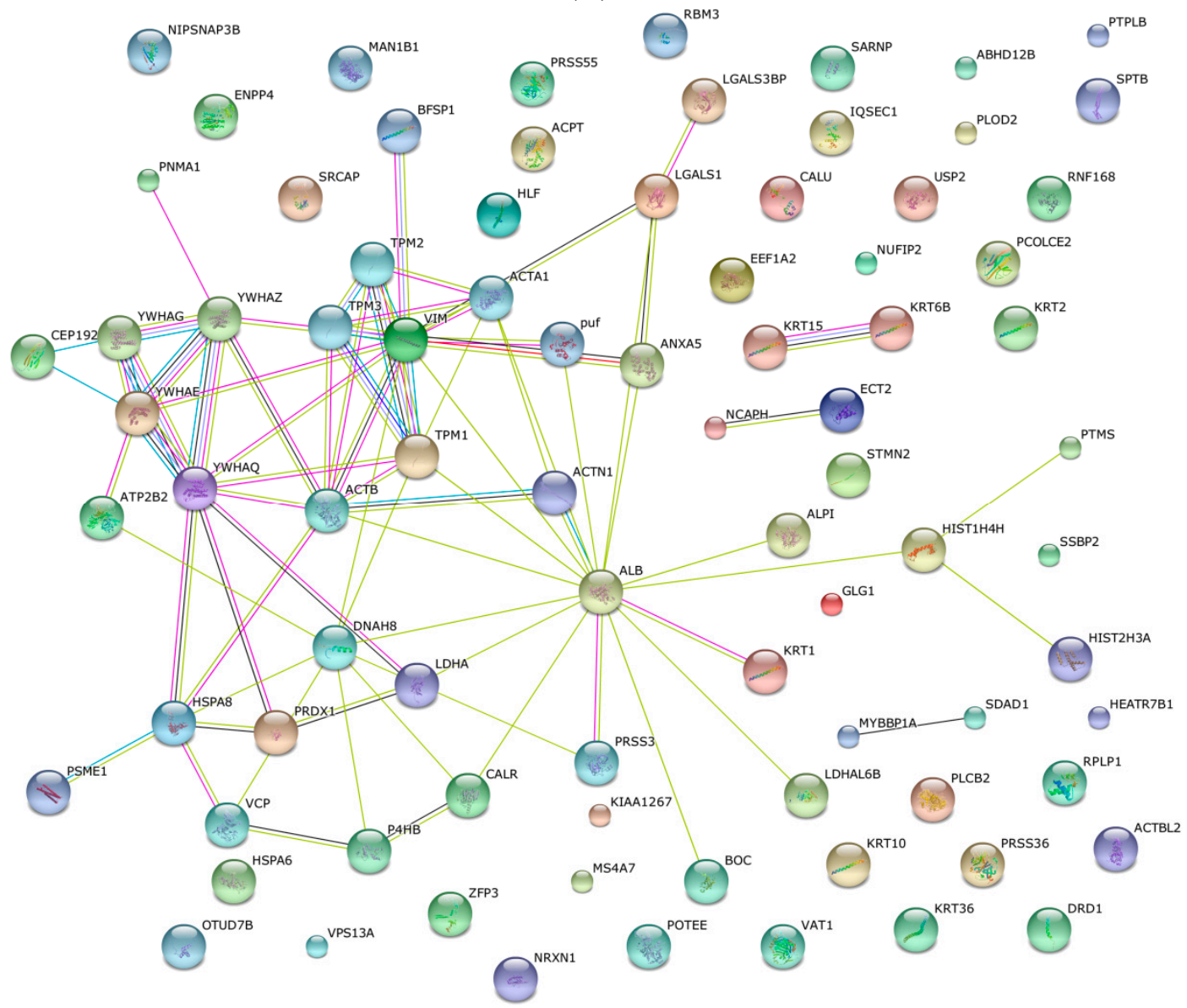

(C) 
Figure 3. Cont.

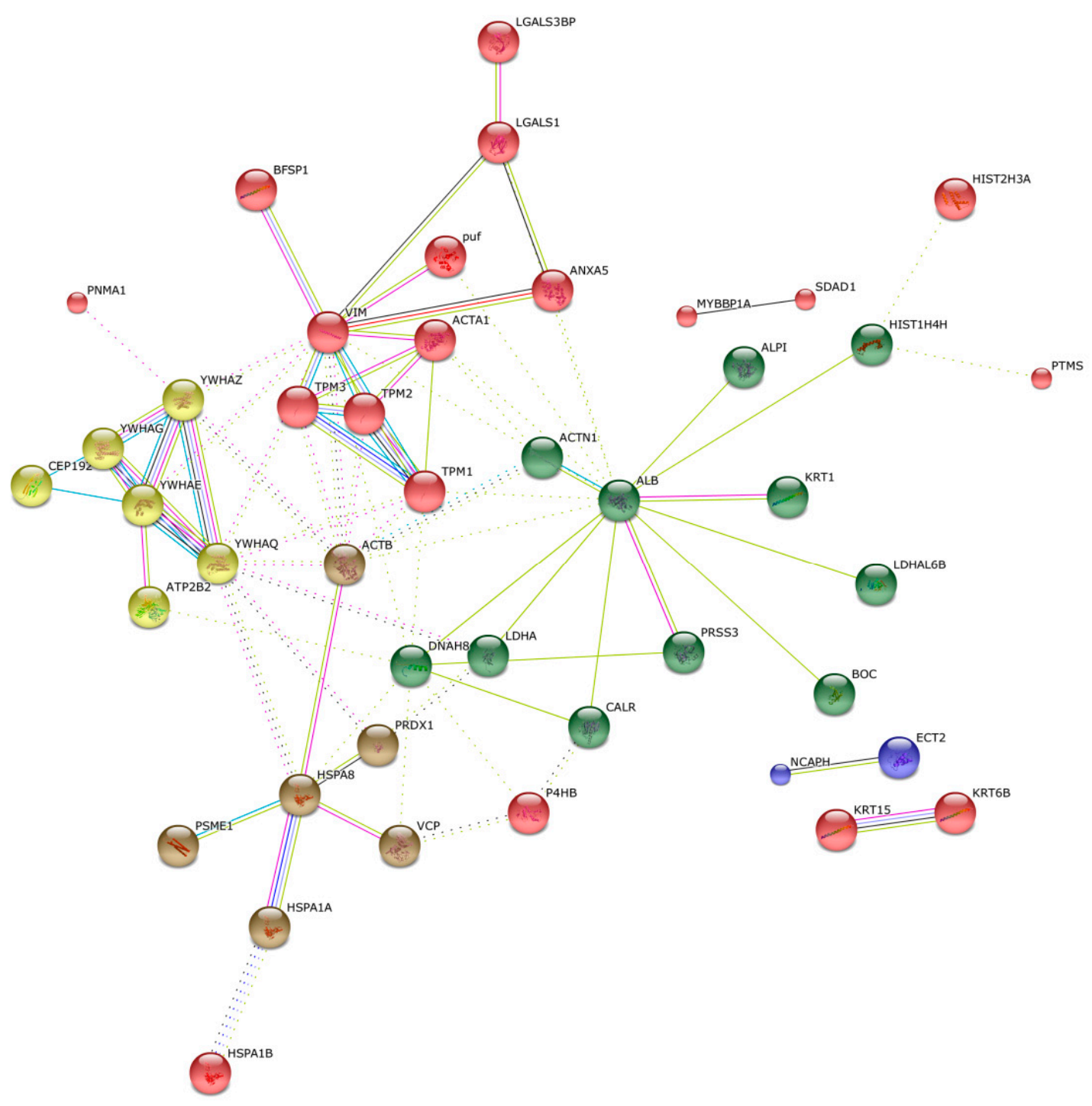

(D)

A total of 90 matched CBGs were queried against the STRING Homo sapiens database to determine their functional relevance (Figure 3C). Through K-mean clustering analysis, associations among TPM1, TPM2, ACTB, DNAH8, and ACTA1; LGALS1, ANXA5, and LGALS3BP; P4HB and CALR; and HSPA1B and HSPA1A were specifically identified in the activated LX-2 cells, whereas associations among YWHAZ, YWHAE, YWHAG, and YWHAQ were specifically identified in the quiescent LX-2 cells (Figure 3D).

The aims of this study were not only to find novel CBGs that differentially expressed in the activated HSCs, but also to speculate the possible pathway networks associated with fibrogenesis in HSCs. Proteins involved in protein processing in ER and calcium signaling pathway were higher expressed in the activated HSCs (Figure 3A,B, and Table S1), which partially demonstrated that these pathways were activated in HSCs when stimulated by TGF- $\beta 1$. Interestingly, the expression levels of galectin-1 (LGALS1) and galectin-3-binding protein (LGALS3BP) were upregulated or specifically identified in the activated LX-2 cells (Table 1). The functions of galectins have been reported to be 
involved in physiological and pathological processes of the liver $[45,46]$. A previous proteomics analysis of rat HSC proteins revealed that the production and secretion of LGALS1 is greatly increased in activated HSCs compared to that in quiescent HSCs [45]. LGALS3 expression was found to be induced in regenerative nodules of liver cirrhosis tissues and in hepatocellular carcinomas [47]. A further study demonstrated that both LGALS1 and LGALS3 activate mitogen-activated protein kinase (MAPK) pathways, presumably by forming cross-links with target molecules through their $\beta$-galactoside-containing glycoconjugates, leading to the proliferation of HSCs [48]. In addition, an increased concentration of cytoplasm $\mathrm{Ca}^{2+}$ can also activate the $\mathrm{Ca}^{2+} /$ calmodulin-dependent protein kinase (CaMKII)/MAPK signaling pathway [49]. Intracellular free $\mathrm{Ca}^{2+}$ is a crucial second messenger that plays various roles in regulating a wide range of cellular processes in different cells and tissues. To maintain a low $\mathrm{Ca}^{2+}$ concentration of $10-100 \mathrm{nM}$ in the cytoplasm, $\mathrm{Ca}^{2+}$ is actively pumped from the cytoplasm to the extracellular space and ER, and sometimes into the mitochondria. Specific signals can trigger an increase in the cytoplasmic $\mathrm{Ca}^{2+}$ level up to $500-1000 \mathrm{nM}$ by opening channels in the plasma membrane or ER [50]. DRD1 is a G protein-coupled receptor that stimulates adenylate cyclase and was found to inhibit $\mathrm{Ca}^{2+}$ from being pumped from the cytosol to the ER [51]. The plasma membrane $\mathrm{Ca}^{2+}$ ATPase (ATP2B) is a transport protein in the plasma membrane of cells that serves to remove $\mathrm{Ca}^{2+}$ from the cytosol [52]. 1-phosphatidylinositol-4,5-bisphosphate phosphodiesterase $\beta-2$ (PLCB2) participates in phosphatidylinositol 4,5-bisphosphate (PIP2) metabolism and indirectly promotes the release of $\mathrm{Ca}^{2+}$ from the ER to the cytosol [53]. According to our results, DRD1 and PLCB2 were specifically identified in the activated LX-2 cells, whereas ATP2B was specifically identified in the quiescent LX-2 cells, indicating that $\mathrm{Ca}^{2+}$ became more inclined to accumulation in the cytoplasm, rather than the extracellular space or the ER in the LX-2 cells activated with TGF- $\beta 1$ (Figure 3B). Thus, it can be conjectured that increases in galectin expression and intracellular $\mathrm{Ca}^{2+}$ concentration might collectively activate the MAPK signaling pathway to realize the activation of HSC induced by TGF- $\beta 1$. This view is different from the traditional view that platelet derived growth factor (PDGF) induced the activation of HSCs through MAPK signaling pathway [54] and TGF- $\beta 1$ through TGF $\beta 1 / A L K 1 /$ Smad1 pathway, and might be therapeutic targets of liver fibrosis. Actually, a recent study suggested that the production of CTGF by TGF- $\beta$ activated MAPK signaling in hepatic progenitor cells [55]. However, the detailed molecular mechanisms of these cytokines still need to be further studied.

\subsection{Expression of PLCB2 in Activated LX-2 Cells and Human Liver Cirrhosis Tissue}

To further validate and investigate the expression of CBGs and their relationship to liver fibrosis and cirrhosis, the increased expression of PLCB2, which was specifically identified in the activated LX-2 cells, was measured in LX-2 cells and human liver by western blotting and immunohistochemistry, respectively. The expression of PLCB2 was found to be distinctly increased in activated, compared with quiescent LX-2 cells (Figure 4A,B) and was also increased in liver cirrhosis tissues compared with normal para-carcinoma tissues (Figure 4C). PLCB2 was found to be mainly distributed in the cytoplasm of the activated LX-2 cells (Figure 4B), as well as that of hepatocytes and sinusoidal cells in liver tissues (Figure 4C). These results were consistent with the MS analysis and 
provided further evidence indicating a possible vital function of PLCB2 in the development of liver fibrosis and cirrhosis.

Figure 4. Expression of PLCB2 in the activated LX-2 cells and human liver cirrhosis tissue. (A) Western blots showed that the expression of PLCB2 was significantly increased in the activated, compared with quiescent LX-2 cells; (B) Immunohistochemistry to validate and investigate the expression and location of PLCB2 in the quiescent and the activated LX-2 cells. The images were shown on the same scale for the quiescent and activated LX-2 cells (images were obtained using a 40× objective lens); (C) Immunohistochemistry to investigate the expression and location of PLCB2 in liver cirrhosis tissues and the normal para-carcinoma tissues. The images were taken using $20 \times$, $40 \times$, and $100 \times$ objective lenses, respectively.
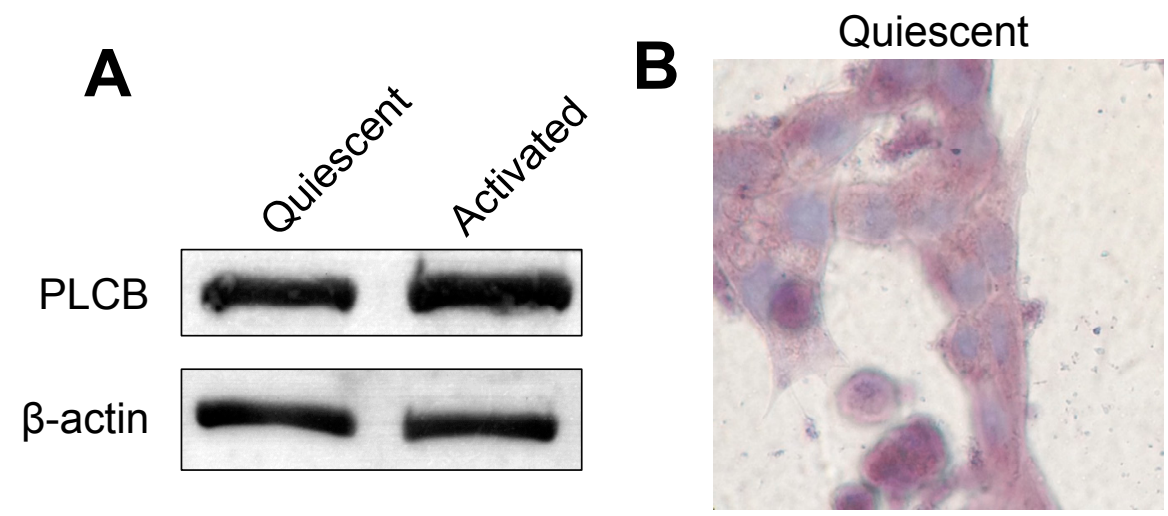

$(40 \times)$

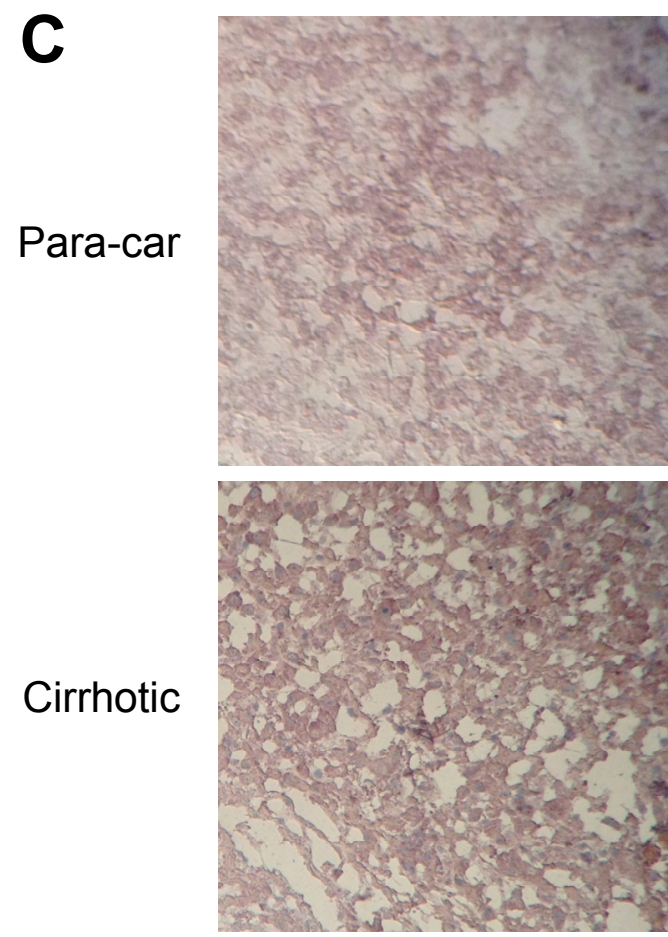

$(20 \times)$
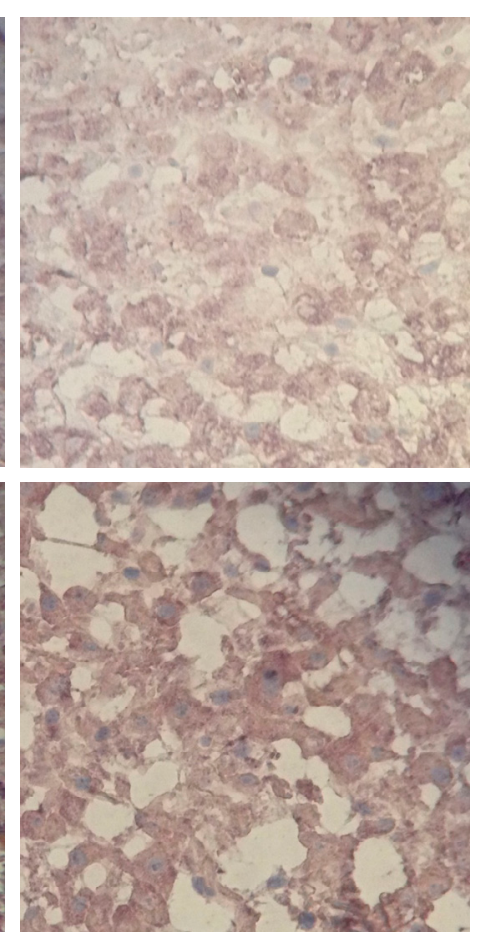

$(40 \times)$

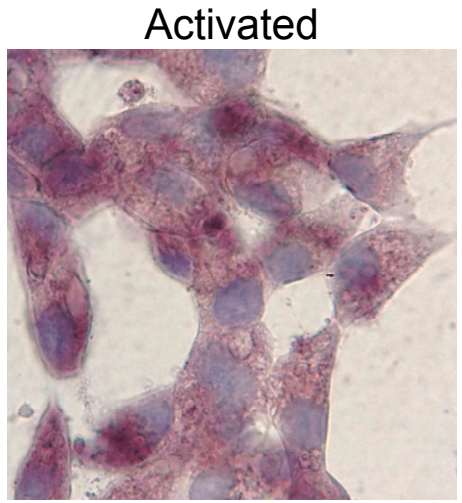

$(40 \times)$
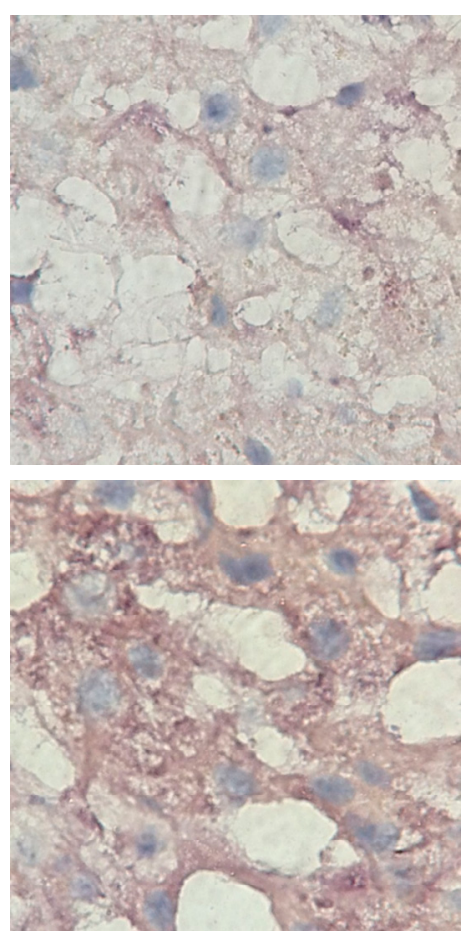

$(100 \times)$

In this study, 62 proteins (30.1\%) were intracellular proteins and $26(12.6 \%)$ were located on the cell membrane, in accordance with the result that ConA showed strong binding to the cytoplasm and/or 
membrane of LX-2 cells in our previous study [18]. The activation of HSCs is a complex and persistent response to chronic liver injury. In the initial stages, HSCs receive paracrine stimulation from cytokines secreted by neighboring cells such as Kupffer cells, hepatocytes, and leukocytes. In the persistent stages, autocrine cytokines (e.g., TGF- $\beta$ and connective tissue growth factor) persistently stimulate HSCs so as to regulate and maintain their activation [56,57]. In this study, a greater number of CBGs were identified from the activated LX-2 cells than from the quiescent LX-2 cells. In addition, glycoproteins involved in the biological processes of response to stimulus, detection of stimulus, and activation of immune response were upregulated in the activated LX-2 cells. For example, PLCB2 was validated to be upregulated in the cytoplasm of the activated LX-2 cells, as well as in the hepatocytes and sinusoidal cells of liver cirrhosis tissues. Based upon the above findings, CBGs might play important roles in signal conduction and response to stimulus, and be associated with the formation and development of liver fibrosis and cirrhosis.

\section{Experimental Section}

\subsection{Materials}

Dulbecco's modified Eagle's medium (DMEM) and fetal bovine serum (FBS) were purchased from Invitrogen (Carlsbad, CA, USA). TGF- $\beta 1$ was purchased from R\&D systems (Minneapolis, MN, USA). Con A was purchased from Vector Laboratories (Burlingame, CA, USA). DTT and iodoacetamide were purchased from GE Healthcare (Little Chalfont, Buckinghamshire, UK). Mouse anti-PLCB2 monoclonal antibody, urea, ammonia bicarbonate $\left(\mathrm{NH}_{4} \mathrm{HCO}_{3}\right)$, sodium periodate $\left(\mathrm{NaIO}_{4}\right)$, HPLC-grade acetonitrile (ACN) and trifluoroacetic acid (TFA), protease inhibitor cocktail, and Bradford assay reagent were purchased from Sigma-Aldrich (St. Louis, MO, USA). Trypsin was purchased from Promega (Madison, WI, USA). Peptide-N-glycosidase F (PNGase F) was purchased from New England Biolabs (Ipswich, MA, USA). Bovine serum albumin (BSA) was purchased from Merck (Darmstadt, Germany). T-PER ${ }^{\circledR}$ reagent was purchased from Pierce Biotechnology (Rockford, IL, USA). Other chemical reagents were obtained from commercial suppliers and used without further purification. All of the solutions were prepared with ultra-pure water obtained from a Milli-Q ${ }^{\circledR} 50 \mathrm{SP}$ Reagent Water System (Millipore, Bradford, MA, USA).

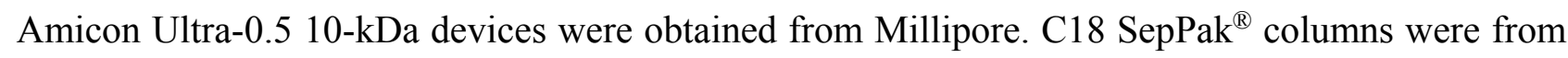
Waters (Milford, CT, USA). The ZHWY- 2101C Oscillator was purchased from ZhiCheng Corporation, China. The SpeedVac ${ }^{\mathrm{TM}}$ vacuum concentrator was obtained from Thermo Scientific (Waltham, MA, USA). Nanospray CHIP-LC-MS/MS 6530 mass spectrometers equipped with HP 1200 solvent delivery systems were purchased from Agilent (Santa Clara, CA, USA).

\subsection{Cell Culture and Stimulation}

The LX-2 cells were a gift from Dr. Friedman of the Mount Sinai School of Medicine, New York, NY, USA. Cells were cultured and stimulated as described previously [18,58]. About $2 \times 10^{5}$ LX-2 cells were seeded and rested in high-glucose DMEM supplemented with 10\% (v/v) FBS for $24 \mathrm{~h}$. After $24 \mathrm{~h}$ of starvation, cells were stimulated by adding $2 \mathrm{ng} / \mathrm{mL}$ TGF- $\beta 1$ for $24 \mathrm{~h}$. The control (quiescent) groups were not treated with TGF- $\beta 1$. 


\subsection{Non-Denaturing Extraction of Total Proteins}

Total protein was extracted from LX-2 cells using non-denaturing T-PER reagent as described previously [18]. The adherent cells were washed twice with ice-cold $1 \times$ PBS $(0.01 \mathrm{M}$ phosphate buffer containing $0.15 \mathrm{M} \mathrm{NaCl}, \mathrm{pH}$ 7.4) to remove culture medium. The cells were incubated for 15 min with T-PER reagent mixed with protease inhibitors $(10 \mu \mathrm{L} / \mathrm{mL}$ T-PER reagent) and then homogenization was achieved by triturating cells with a pipette. Following centrifugation at $10,000 \times g$ for 10 min, the supernatants were either immediately collected for use or stored at $-80{ }^{\circ} \mathrm{C}$. The protein concentration in the supernatants was determined by Bradford assay.

\subsection{Isolation of Glycoproteins from LX-2 Cells Using ConA-Magnetic Particle Conjugates (CMPCs)}

A subset of glycoproteins binding to ConA were selectively isolated by CMPCs as described previously [59,60]. Briefly, $2 \mathrm{mg}$ of total proteins from LX-2 cells were diluted into $600 \mu \mathrm{L}$ of binding buffer (0.1 M Tris- $\mathrm{HCl}, 150 \mathrm{mM} \mathrm{NaCl}, 1 \mathrm{mM} \mathrm{CaCl}, 1 \mathrm{mM} \mathrm{MgCl}_{2}$, and $1 \mathrm{mM} \mathrm{MnCl}_{2}, \mathrm{pH}$ 7.4) supplemented with $1 \%(\mathrm{v} / \mathrm{v})$ proteinase inhibitor. The homemade ConA-magnetic particle conjugates (CMPCs) were rinsed three times with binding buffer and then incubated with proteins at room temperature for $3 \mathrm{~h}$ under gentle shaking. The unbound proteins were removed by washing three times with the rinsing buffer (binding buffer with the addition of $0.1 \%(\mathrm{v} / \mathrm{v})$ Tween 20 ) thoroughly. Then, the glycoproteins bound to CMPCs were eluted with $300 \mu \mathrm{L}$ of the elution buffer (binding buffer supplemented with $0.5 \mathrm{M}$ methyl- $\alpha$-D-mannose, $0.2 \mathrm{M}$ methyl- $\alpha$-D-glucose, and $1 \%(\mathrm{v} / \mathrm{v})$ proteinase inhibitor) at room temperature for $1 \mathrm{~h}$ under gentle shaking, and the supernatants were collected.

\subsection{Identification of Peptides by LC-MS/MS}

The glycoproteins isolated by CMPCs were concentrated and desalted by a size-exclusion spin filter (Amicon Ultra-0.5 $10 \mathrm{~K}$ device), with a molecular mass cutoff of $10 \mathrm{kDa}$. The obtained glycoproteins were denatured in $8 \mathrm{M}$ urea, then deoxidated with $10 \mathrm{mM}$ DTT and carboxyamidomethylated with $20 \mathrm{mM}$ iodoacetamide. Subsequently, trypsin was added at a 1:100 (w/w) ratio of enzyme to protein and the samples were incubated overnight at $37{ }^{\circ} \mathrm{C}$. Glacial acetic acid $(5 \mu \mathrm{L}, \mathrm{pH} 2.0)$ was added to stop the reaction, samples were centrifuged, and the supernatants were collected and lyophilized. Then, the N-linked glycans of the glycopeptides were released by incubation with PNGase F overnight at $37^{\circ} \mathrm{C}$. The peptides were desalted using $\mathrm{C} 18$ SepPak columns and lyophilized. Finally, the peptides were resolubilized in $0.1 \%(\mathrm{v} / \mathrm{v})$ formic acid and analyzed using nanospray CHIP-LC-MS/MS 6530 mass spectrometers equipped with HP 1200 solvent delivery systems.

\subsection{Label-Free Relative Quantification of Identified Glycoproteins by emPAI}

Label-free quantification methods are popular because of their convenience and accuracy. Mascot search engine software (Matrix Science, Boston, MA, USA) includes a semi-quantification method, emPAI, which is a convenient tool for relative quantification [61]. To compare the activated versus quiescent LX-2 glycoproteomes, we calculated normalized emPAI values for each protein (see Formula (1)), and estimated the fold-change in the activated versus quiescent LX-2 cells. When a 
protein was not identified in the quiescent LX-2 cells, we arbitrarily assigned the fold-change as 100 to avoid dividing by zero.

normalized emPAI of a protein $=$ emPAI of that protein/sum of all emPAIs in a sample $\times 100$

\subsection{Data Mining and Bioinformatics}

Ontology analysis was performed according to the standard procedure of Blast2GO [62] to gain insights into functional groupings within the set of identified glycoproteins in three aspects of GO. The differences in the GO terms of glycoproteins between the activated and quiescent LX-2 cells were also discovered by analysis using WEGO [63]. Biological pathways that were enriched in the identified glycoproteins originated from the KEGG human pathway database [64]. To validate the results of Blast2GO and $\mathrm{KEGG}$, an independent functional enrichment analysis was performed using DAVID (Database for Annotation, Visualization and Integrated Discovery) [65]. Finally, to determine the functional relevance of the identified glycoproteins, we performed an analysis of protein association networks using STRING 9.05 [66].

\subsection{SDS-PAGE and Western Blotting}

For SDS-PAGE, protein samples were mixed with $5 \times$ loading buffer and boiled for 4 min at $100{ }^{\circ} \mathrm{C}$, and then separated on a $10 \%$ polyacrylamide resolving gel and a 3\% stacking gel. Molecular mass standards (Thermo Scientific) were run for each gel. Gels were then stained directly with alkaline silver. For western blotting, $30 \mu \mathrm{g}$ of proteins were separated by $10 \%$ SDS-PAGE and then transferred to PVDF membranes (Millipore). After blocking for $2 \mathrm{~h}$ at room temperature with $5 \%(\mathrm{w} / \mathrm{v})$ skimmed milk powder in TBS (100 mM Tris-HCl, $150 \mathrm{mM} \mathrm{NaCl}, \mathrm{pH} 7.6)$, the membrane was incubated overnight at $4{ }^{\circ} \mathrm{C}$ with mouse monoclonal antibodies against PLCB2 in antibody dilution buffer (5\% (w/v) skimmed milk in TBST (0.05\% (v/v) Tween 20 in TBS, pH 7.6)). The membranes were washed three times with TBST, and then incubated with alkaline phosphatase-conjugated secondary antibodies $(1: 1000(\mathrm{v} / \mathrm{v})$ dilution in antibody dilution buffer) for $1 \mathrm{~h}$ at room temperature. The membranes were washed three times with TBST and detected using a 5-bromo-4-chloro-3-indolyl phosphate/nitroblue tetrazolium salt substrate kit. $\beta$-Actin was used as an internal control.

\subsection{Immunohistochemistry}

Immunohistochemistry was performed as described previously [67]. Briefly, $2 \times 10^{5}$ LX-2 cells were seeded in 6-well culture plates containing sterile coverslips. The adherent cells were fixed with $4 \%(\mathrm{w} / \mathrm{v})$ paraformaldehyde and permeabilized in ice-cold $1 \times$ PBS supplemented with $1 \%(\mathrm{v} / \mathrm{v})$ Triton ${ }^{\mathrm{TM}} \mathrm{X}-100$ at $4{ }^{\circ} \mathrm{C}$ for $10 \mathrm{~min}$ and rinsed twice in $1 \times \mathrm{PBS}$. The permeabilized cells were then treated with hydrogen peroxide $\left(\mathrm{H}_{2} \mathrm{O}_{2}\right)(3 \%(\mathrm{v} / \mathrm{v})$ in methanol) for 20 min to block endogenous peroxidase. Prior to incubation with anti-PLCB2, cells were blocked with blocking solution (10\% $(\mathrm{w} / \mathrm{v}) \mathrm{BSA}$ in $1 \times \mathrm{PBS})$ for $1 \mathrm{~h}$ at room temperature. Then, cells were incubated with PLCB2 antibody diluted at 1:1000 in blocking solution overnight at $4{ }^{\circ} \mathrm{C}$. Then, cells were incubated with alkaline phosphatase-conjugated secondary antibodies in blocking solution for $1 \mathrm{~h}$ at room temperature, and horseradish peroxidase colorimetric development solution was applied according to the manufacturer's 
instructions. Finally, the cells were further stained with hematoxylin and histological images were obtained.

\section{Conclusions}

The profile of CBGs in human HSCs (LX-2 cell line) activated with TGF- $\beta 1$ was compared with that of quiescent HSCs by employing a glycoproteomics approach using a CMPCs coupled MS technique. Novel CBGs and the signaling pathways/networks in which they were involved were discovered and partially validated to be connected with the activation of HSCs. The results of this study may provide useful information to aid future investigation to identify new molecular mechanisms for HSC activation and antifibrotic therapeutic targets.

\section{Supplementary Materials}

Supplementary materials can be accessed at: http:/www.mdpi.com/1420-3049/19/12/19845/s1.

\section{Acknowledgments}

This work was supported by National Natural Science Foundation of China (No. 81401137) and the Fundamental Research Funds for the Central Universities, China (No. XJJ2014069).

\section{Author Contributions}

Y.Q. carried out enrichment of CBGs by CMPCs, generated the graphs for proteomic data and wrote the manuscript; Y.Z. participated in the culture and stimulation of LX-2 cells; G.Y. carried out MS identification; T.M. performed the preparation of CMPCs; L.J. participated in data analysis; C.H. participated in the revision of the manuscript; and Z.L. participated in the design of the project, coordination and helped to draft the manuscript. All authors read and approved the final manuscript.

\section{Conflicts of Interest}

The authors declare no conflict of interest.

\section{References}

1. Muhanna, N.; Doron, S.; Wald, O.; Horani, A.; Eid, A.; Pappo, O.; Friedman, S.L.; Safadi, R. Activation of hepatic stellate cells after phagocytosis of lymphocytes: A novel pathway of fibrogenesis. Hepatology 2008, 48, 963-977.

2. Troeger, J.S.; Mederacke, I.; Gwak, G.Y.; Dapito, D.H.; Mu, X.; Hsu, C.C.; Pradere, J.P.; Friedman, R.A.; Schwabe, R.F. Deactivation of hepatic stellate cells during liver fibrosis resolution in mice. Gastroenterology 2012, 143, 1073-1083.

3. Zhao, W.; Zhang, L.; Yin, Z.; Su, W.; Ren, G.; Zhou, C.; You, J.; Fan, J.; Wang, X. Activated hepatic stellate cells promote hepatocellular carcinoma development in immunocompetent mice. Int. J. Cancer 2011, 129, 2651-2661. 
4. Inagaki, Y.; Okazaki, I. Emerging insights into transforming growth factor beta Smad signal in hepatic fibrogenesis. Gut 2007, 56, 284-292.

5. Friedman, S.L. Mechanisms of hepatic fibrogenesis. Gastroenterology 2008, 134, 1655-1669.

6. Garcia-Trevijano, E.R.; Iraburu, M.J.; Fontana, L. Transforming growth factor beta1 induces the expression of alpha1 (I) procollagen mRNA by a hydrogen peroxide-C/EBPbeta-dependent mechanism in rat hepatic stellate cells. Hepatology 1999, 29, 960-970.

7. Varki, A. Essentials of Glycobiology; Cold Spring Harbor Laboratory Press: New York, NY, USA, 2009.

8. Gerald, W.H.; Ronald, J. Glycomics hits the big time. Cell 2010, 143, 672-676.

9. Li, D.; Mallorya, T.; Satomura, S. AFP-L3: A new generation of tumor marker for hepatocellular carcinoma. Clin. Chim. Acta 2001, 313, 15-19.

10. Lee, L.Y.; Thaysen-Andersen, M.; Baker, M.S.; Packer, N.H.; Hancock, W.S.; Fanayan, S. Comprehensive $\mathrm{N}$-glycome profiling of cultured human epithelial breast cells identifies unique secretome $\mathrm{N}$-glycosylation signatures enabling tumorigenic subtype classification. J. Proteome Res. 2014, in press.

11. Goto, Y.; Obata, T.; Kunisawa, J.; Sato, S.; Ivanov, I.; Lamichhane, A.; Takeyama, N. Innate lymphoid cells regulate intestinal epithelial cell glycosylation. Science 2014, 345, 1254009.

12. Chen, Y.X.; Weng, Z.H.; Zhang, S.L. Notch3 regulates the activation of hepatic stellate cells. World J. Gastroenterol. 2012, 18, 1397-1403.

13. Moloney, D.J.; Panin, V.M.; Johnston, S.H.; Chen, J.; Shao, L.; Wilson, R.; Wang, Y.; Stanley, P.; Irvine, K.D.; Haltiwanger, R.S.; et al. Fringe is a glycosyltransferase that modifies Notch. Nature 2000, 406, 369-375.

14. Muchmore, A.V.; Decker, J.M. The lectin-like interaction between recombinant tumor necrosis factor and uromodulin. J. Immunol. 1987, 138, 2541-2546.

15. Cebo, C.; Dambrouck, E.; Maes, C.; Laden, G.; Strecker, J.C.; Michalski, J.P.; Zanetta, J.P. Recombinant human interleukins IL-1alpha, IL-1beta, IL-4, IL-6, and IL-7 show different and specific calcium-independent carbohydrate-binding properties. J. Biol. Chem. 2001, 276, 5685-5691.

16. Hellerbrand, C.; Jobin, C.; Licato, L.L.; Sartor, R.B.; Brenner, D.A. Cytokines induce NF-kappaB in activated but not in quiescent rat hepatic stellate cells. Am. J. Physiol. 1998, 275, G269-G278.

17. Spratte, J.; Meyer, Z.S.H.; Endlich, N.; Zygmunt, M.; Fluhr, H. Heparin inhibits TNF- $\alpha$ signaling in human endometrial stromal cells by interaction with NF-кB. Mol. Hum. Reprod. 2013, 19, 227-236.

18. Qin, Y.; Zhong, Y.; Dang, L.; Zhu, M.; Yu, H.; Chen, W.; Cui, J.; Bian, H.; Li, Z. Alteration of protein glycosylation in human hepatic stellate cells activated with transforming growth factor- $\beta 1$. J. Proteomics 2012, 75, 4114-4123.

19. Spicer, S.S.; Schulte, B.A. Diversity of cell glycoconjugates shown histochemically: A perspective. J. Histochem. Cytochem. 1992, 40, 1-38.

20. Yue, T.; Goldstein, I.J.; Hollingsworth, M.A.; Kaul, K.; Brand, R.E.; Haab, B.B. The prevalence and nature of glycan alterations on specific proteins in pancreatic cancer patients revealed using antibody-lectin Sandwich arrays. Mol. Cell Proteomics 2009, 8, 1697-1707. 
21. Zhang, H.; Li, X.J.; Martin, D.B.; Aebersold, R. Identification and quantification of N-linked glycoproteins using hydrazide chemistry, stable isotope labeling and mass spectrometry. Nat. Biotechnol. 2003, 21, 660-666.

22. Tian, Y.A.; Zhou, Y.; Elliott, S.; Aebersold, R.; Zhang, H. Solid-phase extraction of N-linked glycopeptides. Nat. Protoc. 2007, 2, 334-339.

23. Kaji, H.; Saito, H.; Yamauchi, Y.; Shinkawa, T.; Taoka, M.; Hirabayashi, J. Lectin affinity capture, isotope-coded tagging and mass spectrometry to identify N-linked glycoproteins. Nat. Biotechnol. 2003, 21, 667-672.

24. Kaji, H.; Yamauchi, Y.; Takahashi, N.; Isobe, T. Mass spectrometric identification of N-linked glycopeptides using lectin-mediated affinity capture and glycosylation site-specific stable isotope tagging. Nat. Protoc. 2007, 1, 3019-3027.

25. Sturiale, L.; Barone, R.; Palmigiano, A.; Ndosimao, C.N.; Briones, P.; Adamowicz, M. Multiplexed glycoproteomic analysis of glycosylation disorders by sequential yolk immunoglobulins immunoseparation and MALDI-TOF MS. Proteomics 2008, 8, 3822-3832.

26. Cho, W.; Jung, K.; Regnier, F.E. Use of glycan targeting antibodies to identify cancer-associated glycoproteins in plasma of breast cancer patients. Anal. Chem. 2008, 80, 5286-5292.

27. Sparbier, K.; Asperger, A.; Resemann, A.; Kessler, I.; Koch, S.; Wenzel, T. Analysis of glycoproteins in human serum by means of glycospecific magnetic bead separation and LC-MALDI-TOF/TOF analysis with automated glycopeptide detection. J. Biomol. Tech. 2007, 18, 252-258.

28. Xu, Y.; Wu, Z.; Zhang, L.; Lu, H.; Yang, P.; Webley, P.A. Highly specific enrichment of glycopeptides using boronic acid-functionalized mesoporous silica. Anal. Chem. 2008, 81, 503-508.

29. Alvarez-Manilla, G.A.; Guo, Y.; Warren, N.L.; Orlando, R.; Pierce, M. Tools for glycoproteomic analysis: size exclusion chromatography facilitates identification of tryptic glycopeptides with N-linked glycosylation sites. J. Proteome Res. 2006, 5, 701-708.

30. Jia, W.; Lu, Z.; Fu, Y.; Wang, H.P.; Wang, L.H.; Chi, H. A strategy for precise and large scale identification of core fucosylated glycoproteins. Mol. Cell Proteomics 2009, 8, 913-923.

31. Lewandrowski, U.; Lohrig, K.; Zahedi, R.; Wolters, D.; Sickmann, A. Glycosylation site analysis of human platelets by electrostatic repulsion hydrophilic interaction chromatography. Clin. Proteomics 2008, 4, 25-36.

32. Zhang, H.; Guo, T.; Li, X.; Datta, A.; Park, J.E.; Yang, J. Simultaneous characterization of glyco- and phosphoproteomes of mouse brain membrane proteome with electrostatic repulsion hydrophilic interaction chromatography. Mol. Cell. Proteomics 2010, 9, 635-647.

33. Gupta, R.; Jung, E.; Brunak, S. Prediction of N-glycosylation Sites in Human Proteins. In Preparation, 2004. Available online: http://www.cbs.dtu.dk/services/NetNGlyc/ (accessed on 25 September 2014).

34. Steentoft, C.; Vakhrushev, S.Y.; Joshi, H.J.; Kong, Y.; Vester-Christensen, M.B.; Schjoldager, K.T.; Lavrsen, K.; Dabelsteen, S.; Pedersen, N.B.; Marcos-Silva, L.; et al. Precision mapping of the human $O$-GalNAc glycoproteome through SimpleCell technology. EMBO J. 2013, 32, 1478-1488.

35. Goldstein, I.J.; Poretz, R.D. Isolation, physicochemical characterization and carbohydrate-binding specificity of lectins. In The Lectins: Properties, Functions, and Applications in Biology and Medicine; Liener, I.E., Sharon, N., Goldstein, I.J., Eds.; Academic Press: New York, NY, USA, 1986; pp. 33-247. 
36. Apweiler, R.; Jesus Martin, M.; O’onovan, C.; Magrane, M.; Alam-Faruque, Y.; Antunes, R. The UniProt Consortium: Reorganizing the protein space at the Universal Protein Resource (UniProt). Nucl. Acids Res. 2012, 40, D71-D75.

37. Aebi, M.; Bernasconi R.; Clerc S.; Molinari M. N-glycan structures: Recognition and processing in the ER. Cell 2010, 35, 74-82.

38. Helenius, A.; Aebi, M. Intracellular functions of N-Linked glycans. Science 2001, 291, 2364-2369.

39. Naismith, J.H.; Field, R.A. Structural basis of trimannoside recognition by concanavalin A. J. Biol. Chem. 1996, 271, 972-976.

40. Ahn, J.; Febbraio, M.; Silverstein, R.L. A novel isoform of human Golgi complex-localized glycoprotein-1 (also known as E-selectin ligand-1, MG-160 and cysteine-rich fibroblast growth factor receptor) targets differential subcellular localization. J. Cell Sci. 2005, 118, 1725-1731.

41. Kowalewski, B.; Lübke, T.; Kollmann, K.; Braulke, T.; Reinheckel, T.; Dierks, T.; Damme, M. Molecular Characterization of Arylsulfatase G: Expression, processing, glycosylation, transport, and activity. J. Biol. Chem. 2014, 289, 27992-28005.

42. Reily, C.; Ueda, H.; Huang, Z.Q.; Mestecky, J.; Julian, B.A.; Willey, C.D.; Novak, J. Cellular signaling and production of galactose-deficient IgA1 in IgA nephropathy, an autoimmune disease. J. Immunol. Res. 2014, 2014, doi:10.1155/2014/197548.

43. Lin, M.C.; Huang, M.J.; Liu, C.H.; Yang, T.L.; Huang, M.C. GALNT2 enhances migration and invasion of oral squamous cell carcinoma by regulating EGFR glycosylation and activity. Oral Oncol. 2014, 50, 478-484.

44. Zachara, N.E.; Hart, G.W. Cell signaling, the essential role of O-GlcNAc! Biochim. Biophys. Acta 2006, 1761, 599-617.

45. Kristensen, D.B.; Kawada, N.; Imamura, K.; Miyamoto, Y.; Tateno, C.; Seki, S.; Kuroki, T.; Yoshizato, K. Proteome analysis of rat hepatic stellate cells. Hepatology 2000, 32, 268-277.

46. Santucci, L.; Fiorucci, S.; Cammilleri, F.; Servillo, G.; Federici, B.; Morelli, A. Galectin-1 exerts immunomodulatory and protective effects on concanavalin A-induced hepatitis in mice. Hepatology 2000, 31, 399-406.

47. Hsu, D.K.; Dowling, C.A.; Jeng, K.C.; Chen, J.T.; Yang, R.Y.; Liu, F.T. Galectin-3 expression is induced in cirrhotic liver and hepatocellular carcinoma. Int. J. Cancer 1999, 81, 519-526.

48. Maeda, N.; Kawada, N.; Seki, S.; Arakawa, T.; Ikeda, K.; Iwao, H.; Okuyama, H.; Hirabayashi, J.; Kasai, K.; Yoshizato, K. Stimulation of proliferation of rat hepatic stellate cells by galectin-1 and galectin-3 through different intracellular signaling pathways. J. Biol. Chem. 2003, 278, 18938-18944.

49. Huang, Y.; Li, X.; Wang, Y.; Wang, H.; Huang, C.; Li, J. Endoplasmic reticulum stress-induced hepatic stellate cell apoptosis through calcium-mediated JNK/P38 MAPK and Calpain/Caspase-12 pathways. Mol. Cell Biochem. 2014, 394, 1-12.

50. Berridge, M.J.; Peter, B.M.D. The versatility and universality of calcium signalling. Nat. Rev. Mol. Cell Biol. 2000, 1, 11-21.

51. Clapham, D.E. Calcium signaling. Cell 2007, 131, 1047-1058.

52. Verma, A.K.; Filoteo, A.G.; Stanford, D.R.; Wieben, E.D.; Penniston, J.T. Complete primary structure of a human plasma membrane $\mathrm{Ca}^{2+}$ pump. J. Biol. Chem. 1988, 263, 14152-14159.

53. Singer, A.U.; Waldo, G.L.; Harden, T.K.; Sondek, J. A unique fold of phospholipase C-beta mediates dimerization and interaction with G alpha q. Nat. Struct. Biol. 2002, 9, 32-36. 
54. Wu, F.R.; Pan, C.X.; Rong, C.; Xia, Q.; Yuan, F.L.; Tang, J.; Wang, X.Y.; Wang, N.; Ni, W.L.; Chen, F.H. Inhibition of acid-sensing ion channel 1a in hepatic stellate cells attenuates PDGF-induced activation of HSCs through MAPK pathway. Mol. Cell. Biochem. 2014, 395, 199-209.

55. Ding, Z.Y.; Jin, G.N.; Liang, H.F.; Wang, W.; Chen, W.X.; Datta, P.K.; Zhang, M.Z.; Zhang, B.; Chen, X.P. Transforming growth factor $\beta$ induces expression of connective tissue growth factor in hepatic progenitor cells through Smad independent signaling. Cell Signal 2013, 25, 1981-1992.

56. Friedman, S.L. Cytokines and fibrogenesis. Semin. Liver Dis. 1999, 19, 129-140.

57. Pinzani. M.; Marra, F. Cytokine receptors and signaling in hepatic stellate cells. Semin. Liver Dis. 2001, 21, 397-416.

58. Li, Y.L.; Wu, J.; Wei, D.; Zhang, D.W.; Feng, H.; Chen, Z.N. Newcastle disease virus represses the activation of human hepatic stellate cells and reverses the development of hepatic fibrosis in mice. Liver Int. 2009, 29, 593-602.

59. Yang, G.; Cui, T.; Chen, Q.; Ma, T.; Li, Z. Isolation and identification of native membrane glycoproteins from living cell by concanavalin A-Magnetic particle conjugates. Anal. Biochem. 2012, 421, 339-341.

60. Yang, G.; Cui, T.; Wang, Y.; Sun, S.; Ma, T.; Wang, T.; Chen, Q.; Li, Z. Selective isolation and analysis of glycoprotein fractions and their glycomes from hepatocellular carcinoma sera. Proteomics 2013, 13, 1481-1498.

61. Ishihama, Y.; Oda, Y.; Tabata, T.; Sato, T.; Nagasu, T.; Rappsilber, J.; Mann, M. Exponentially modified protein abundance index (emPAI) for estimation of absolute protein amount in proteomics by the number of sequenced peptides per protein. Mol. Cell Proteomics 2005, 4, 1265-1272.

62. Conesa, A.; Götz, S.; Garcia-Gomez, J.M.; Terol, J.; Talon, M.; Robles, M. Blast2GO: A universal tool for annotation, visualization and analysis in functional genomics research. Bioinformatics 2005, 21, 3674-3676.

63. Ye, J.; Fang, L.; Zheng, H.; Zhang, Y.; Chen, J.; Zhang, Z.; Wang, J.; Li, S.; Li, R.; Bolund, L.; et al. WEGO: A web tool for plotting GO annotations. Nucl. Acids Res. 2006, 34, W293-W297.

64. Kanehisa, M.; Goto, S.; Sato, Y.; Furumichi, M.; Tanabe, M. KEGG for integration and interpretation of large-scale molecular datasets. Nucl. Acids Res. 2012, 40, D109-D114.

65. Huang, D.W.; Sherman, B.T.; Lempicki, R.A. Systematic and integrative analysis of large gene lists using DAVID Bioinformatics Resources. Nat. Protoc. 2009, 4, 44-57.

66. Szklarczyk, D.; Franceschini, A.; Kuhn, M.; Simonovic, M.; Roth, A.; Minguez, P. The STRING database in 2011: Functional interaction networks of proteins, globally integrated and scored. Nucl. Acids Res. 2011, 39, D561-D568.

67. Gomes, T.S.; Oshima, C.T.; Forones, N.M.; de Oliveira Lima, F.; Ribeiro, D.A. Expression of galectin-3 in gastric adenocarcinoma. Indian J. Med. Res. 2014, 140, 69-76.

Sample Availability: Samples of the compounds upon request are available from the authors.

(C) 2014 by the authors; licensee MDPI, Basel, Switzerland. This article is an open access article distributed under the terms and conditions of the Creative Commons Attribution license (http://creativecommons.org/licenses/by/4.0/). 